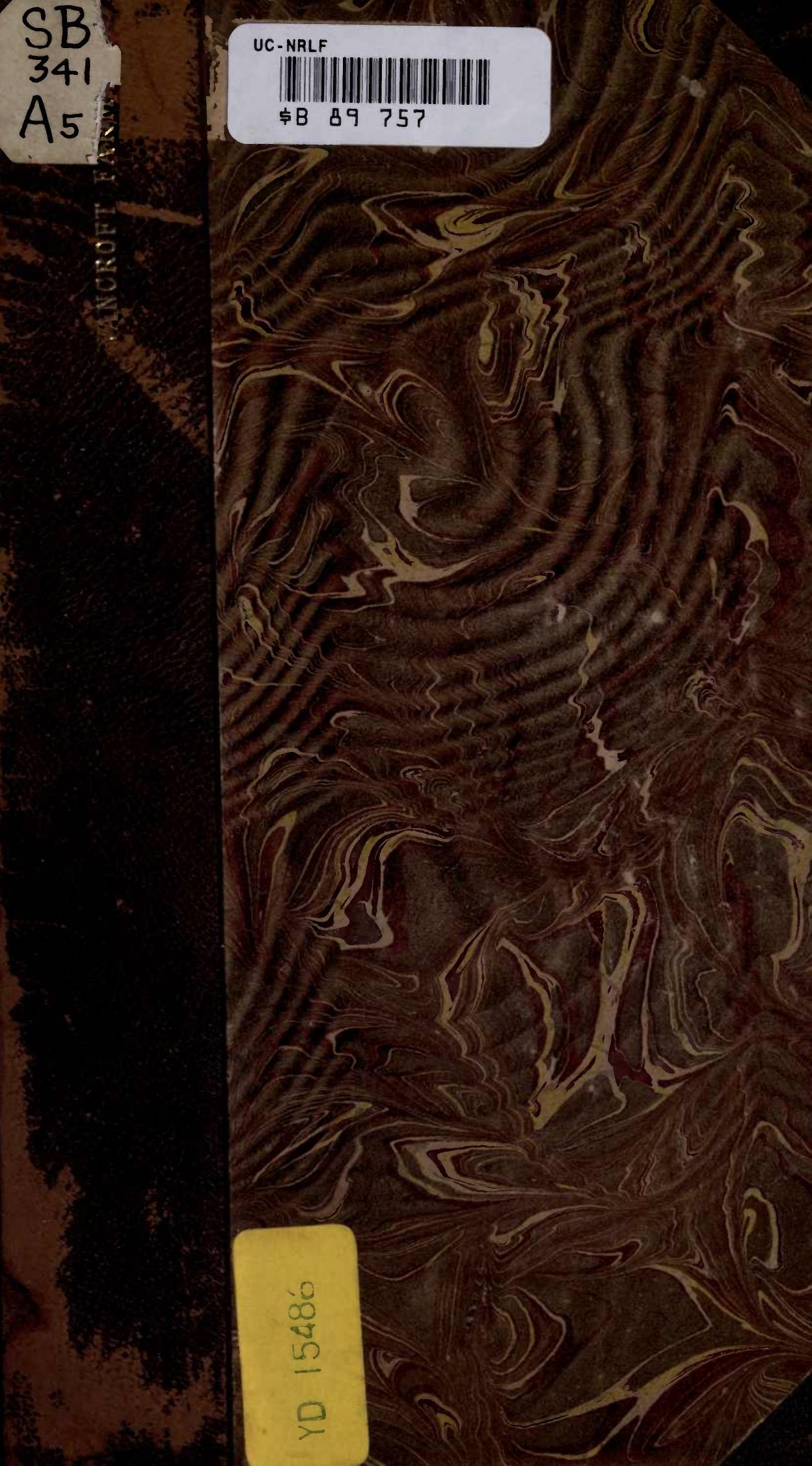




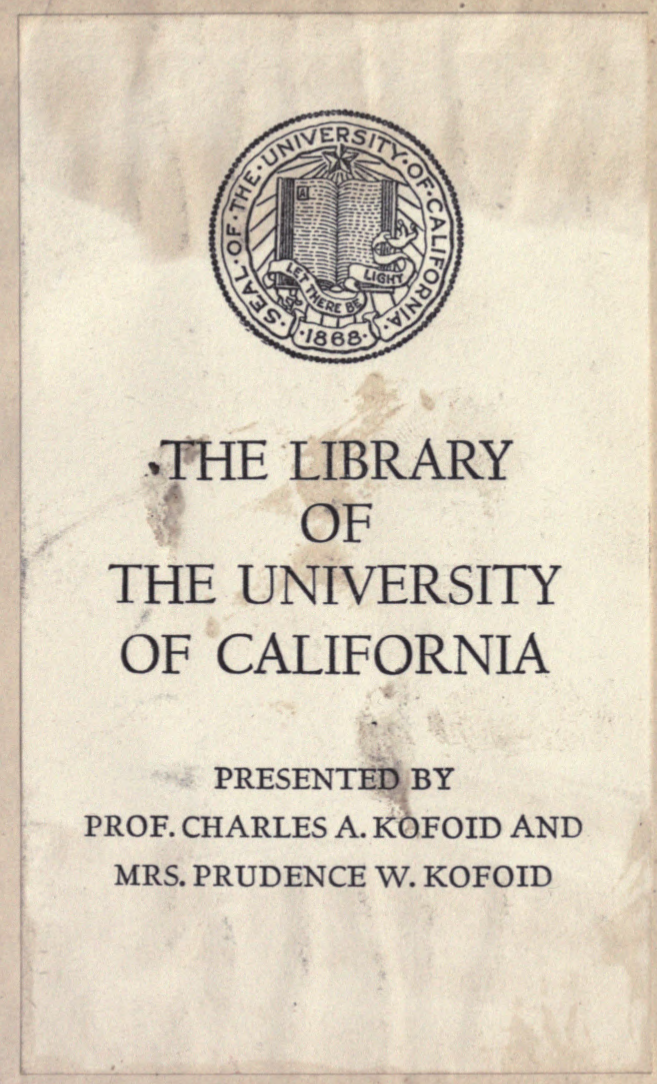





\begin{abstract}
Amerucan agreceleveceh.
ONION CULTURE.

น น ก น น น น

Prize Essays and other Papers.

P U B L I S E R S' PREF A C E.

Seventeen of the following articles, as numbered in order, were written in response to a PREMTUM offered by the American Agriculturist, (New York,) " for the best plaiu practical directions on raising onions; to be written by an experienced Onion Grower; not to exceed twelve pages of manuscript; to embrace the various items, from the selection of the seed to marketing the crop-all written out so plainly as to be useful to those who have had little or no experience in the cultivation of the crop." Many articles were received from various parts of the country, all of which were of more or less value. As but one or two only could be given in the American Agriculturist, a selection was made of the Essays giving the greatest variety of experience, and published in the present form. The work at once became the standard authority on Onion Culture, and edition after edition was called for. In revising the work and bringing it fully down to date, it bas been essentially enlarged by the addition of valuable matter. Wherever the prices of onions are mentioned in the following pages, they are those which prevailed at the time when the Essay was written. The current inarket rates are given in the Caily papers of large cities.
\end{abstract}

No. I.

[Tras writer of the following has, we believe, had an expenence of some thirty years in growng omone cor market. - ED. $]$

BY WM. J. JENNINGS, OF WESTPORT, CT.

SzLisotios of Ground. - A deep loamy soil is consdered the best for onions, though they will grow on soil a large proportion of which is clay. A light porous soil with a gravelly subsoil should be avoided. The surface of the ground should be nearly level, as hilly ground is liable to wash from heavy rains. In selecting a piece of ground for onions, there are sevoral things that should be considered.

1st. Ground that is stony should be avoided, unless the cost of removing the stones is first considered.

$2 \mathrm{~d}$. Ground that is overrun by weeds and troublesome grasses, should not be chosen until they are first subdued.

3d. Grosnd that is shaded will not do; neither that which is too wet to be worked early in the spring.

Having attended to the foregoing hints, it is also important to select with reference to cultivating the same ground for onions for an indefinite length of time, for in so doing, the labor of first preparation is avoided; orides, each succeoding crop is more easily cultivated, provided the previous work has been thoronghly tone.
Preparation of Ground fọ Sowing.- - Having made a suitable selection of ground, the next thing to be considered is its preparation. First gather out the stones pretty thoroughly - putting the largest ones into fences, the middling-sized ones into blind ditches, and the smallest ones into the mud-holes of the roads. In this way some good is done. Above all, avoid the heathenish practice of emptying them by the roadside, not only disfiguring the roads, but giving a harbor for briers, elders, and the ten thousand noxious weeds that now infest such places. In the next place give the ground a heavy coat of the best manure Hog-pen is the best home-made manure; next, stable if not too coarse; next, common barnyard, well rotted As to the quantity of manure on an acre, that must be determined in part by the condition of the soil. From twenty to thirty loads of forty bushels per load. make a very good coat to begin with. After this is deeply ploughed in, a top dressing of wood ashes $\rightarrow$ ay 150 or 200 bushels to the acre, may be given, or from $30 n$ to $500 \mathrm{lbs}$. of guano, or bolles ground or sawed 
nre good, or any well-pulverized manure that will not be in the way of the harrow and rake may be ve used. But take care not to use seedy manure if you wish to save much labor and patience. Manure may be carted on and ploughed under in the fall, or in the spring just before sowing. If the ground is ploughed in the fall, it will not be necessary to replough in the spring. Fall ploughing should be put off as long as possible-say to the middle of November.

Having manured and ploughed your ground, it is now to be harrowed and raked, until it is as even and smonth as a beet-bed. Harrows of either irnn or wooden teeth are first used to bring the ground to a general level, and the stones to the surface; the brush or bush-harrows are then used until the lumps are pulverized, and the surface of the ground made smooth, then wooden hand-rakes, of twelve teeth each, are applied to take off the small stones and finish for sowing.

Manure for top-dressing may be harrowed or raked in, and if guano is used, it is well to make a second application during the growth of the crop, which may be scuffled in by the hoe. All manure used should be ploughed under or mixed with the soil immediately after it is spread.

SowLa.-Now then the seed is to be committed to the ground. Aud here a word or two of caution is necessary. Be careful what seed is sown. If you are ander the necessity of buying seed, procure it of some reliable man, a regular, honest onion-grower. It sbould not be over one year old, and should $\operatorname{sink}$ when placed in water. Better not trust to seed-merchants, unless actually obliged to. Rather pay $\$ 5$ per pound for reliable seed, than get doubtful seed for nothing. Having obtained your seed, say from three to four lbs. per acre, you now proceed to deposit it in the ground, which is done, where onions are raised to much extent, by a simple machine, (costing $\$ 5$,) drawn by band, making two drills twelve inches apart, and dropping the seed in them at the same time. Next comes the covering process, which consists in drawing w hand-roller over the groand lengthwise the rows; $r$, which is the most common way, pushing a clean oright kne over the drills. This may be done by voys, as they make smaller and lighter tracks than men. Commence the work straight, and then be careful to keep it 80; not but that crooked rows make straight onions, but for the beatity and neatness of the thing. $\Delta$ man accustomed to it will sow three acres a day. The time for sowing is the month of April, earlier or later, according to the state of the ground. It is generally found that the earliest-sowed onions, other things being equal, $d ?$ the best.

Cultivatiox.-About four weeks from the time of sowing, cultration commences in earnest. The first ching to be done in this depariment is to go through them with an onion hoo. as scon as the rows can be distinctly seen, when the dew is on in the morning. The hoeing this time must be light-just skimming the top of the ground-the hoe being put forward and drawn toward the hoer. In the course of a few days weeding must be commenced; removing all the weeds from among the onions. This part of the work is usually performed by boys, for various reasons - 1 st. Because they can be hired for about half the price of men. 2d. A good active boy, fifteen or sixteen years old, can do as much, or more work than a man; and also because it is less tiresome for boys than full-grown men : for it must be remembered that the stooping or crawling posture must be assumed in weeding onions. In other words, whoever does this work must get down to them, eyes, fingers, and all, and not be ashamed of his occupation, or of soiling his clothes. The tools needed for hoeing and weeding onions are few and simple. The most approved hoe in use, 18 uscally made from a buck-saw plate, either new ur worn, cut about eight inches in length, and from 0.10 to two inches in wiath, with a goose-neck riveted on the inside of it; or to make the hoe stiffer, two goose. necks are used, riveted as before, but about one and a half inches from the ends of the plate, and uniting in one shank in the handle, which may be about five feet long. This hoe should be kept clean and bright, so that the dirt will slide over it without being much displaced. A push or scuffle-hoe is sometimes used in the advanced growth of the crop. The tools used for weeding, aside from what nature has prcarided, are a crooked knife, (common case or shoe-knife with the lower end bent up, ) and a weeder made of thin steel plate, about two inches long and one wide, riveted with a goose-neck, like the hoes, and fixed in a handle about eight inches long. Later in the season, a larger weeder is used, about four inches in length, and set in a handlo about two feet long. This is used, when the onion-tops have become large, for the purpose of taking out single weeds, and when hoeing the ground would injure the onions.

After this description of tools, we will return to hoeing and weeding. As no definite rule can be giv. en for the number of hoeings or weedings, this must be left to the discretion of the owner, or the person in charge. Suffice it to say, the oftener the ground is stirred, the better for the crop. Ground should usu. ally be hoed about once in two weeks during the earlier part of the season, and the weeding must be governed by numbers and growth of the weeds. It is all-important that the weeds be not suffered to get the advantage. Keep them down-keep them out-be vigilant. Think of the old adage about the stitch in time, and apply it here.

This same vigilance must be exercised during the growth of the crop. Some persons, owing to extra work during harvest, are apt to neglect their onions This should never be. July is an important month to 
the onion-grower. If neglected then, the crop is as good as half-lost. Neither is it true that onions are injured by working among them when bottoming, although care is necessary not to knock down the tops, nor disturb the bulbs when growing; but bad usage is better than entire neglect. Neither should weeds be permitted to go to seed on the ground intended for onio $s$ s the next year, after the crop is removed. It is sometimes necessary to hoo the ground over entirely, and carry off the weeds that may have grown after the onions have been pulled. The great pest of onionground usually is purslain; and this must be watched and lealt with in a summary way. It may be hardly necessary to suggest here that the fences and horders of onion-grounds should be kept entirely clean and tidy.

A man will hoe from half an acre to an acre of onious in a day. A smart boy will take care of from one to two acres of ground during the season, and have an odd day now and then to go fishing.

HARVESTING.-This takes place during the latter part uf August, and first of September. The time to pull onions, (which should be done by hand,) is when the topa have fallen down and turned a brown or yellowish color. Sometimes on account of the season, or seed, or both, there will be more or less that will not drop down and dry up. Some have proposed in such cases to roll a barrel over them, or break them down in some way, but it is of doubtful expediency. A scallion will be such, whether standing up or bent down. When the main crop has ripened down, it is best to pull them all, and sort out those which are not it for market, to feed out to the cattle; for which purpose they are esteemed of considerable value. The cattle generally devour them greedily; they shonld not however be fed to milch cows.

The most approved way of curing onions after they are pulled, is, to let them lie scattered about the ground for about three days, and then pile them up in small stacks, containing about a barrel each : after remaining so about two weeks, open them, and give them frequent stirrings for about three bright drying days, then house them in a perfectly dry condition. The stacking gives them an opportunity to sweat, and keeps them in a measure from the weather, so tha when opened, the outside skin shells off, and gives them a brighter and clearer appearance, than they would have if left to cure, scattered about the field.

Onions cured in this way may be put up in bins, or bays to the depth of four or fire feet, without any danger of injury; there to be kept, if desired, until the following spring, provided the tops are left on them. If put in barn bays, a rough floor should be laid down on timber a few inches from the ground, in order that a circulation of air underneath may be obtained. Onions should not be kept in cellars unless reroarkably dry and cool. A slight freezing does not burt them, provided they are not disturbed in their rozen state
MARKETING.-Th s may commence as soon as omions are ripe, and continue until the middle of May follow ing, provided communication is open. The most com. mon way of sending onions to market, is by putting them in barrels with one head, and sending them in vessels; as freight by water is cheaper than by land. This holds good, however, only for those who are for. tunate enough to live in proximity to the water.

All the preparation onions require for market, is to cut or strip off their tops and put them in barrels A man or boy will prepare fifty bushels in a day. Onions always keep best in their tops; therefore they should not be removed until ready for market.

The price of onions varies from $\$ 1.00$ to $\$ 5.00$ pet barrel, but the average net price, taking one year with another for several years back, has been about $\$ 1.50$ per barrel.

The onions sent to New-York market are usually wholsaled from vessels to the dealers, and resold by them in smaller lots, they selling from 25 to 50 cents per barrel, in advance of cost, so that by the time the consumer gets them the first price is nearly douhled.

General ReMark8-There is no crop, perhapa more sure than that of onions, They are liable, it is true, to blight, but this seldom occurs unless they are neglected. Rich soil, with a good application of mar nure every year, and proper attention, will almost in. variably insure a good crop. Five hundred bushels to an acre is an average crop, though eight hundred aro frequently raised.

There are three varieties of onions commonly raised, namely, red, white, and yellow. The red onions take the lead, as they are more hardy, grow better, and bear handling better than either of the other kinds. The foregoing directions apply equally to each variety, though white ones require more attention in curing, and gentler handling. White onions in limited quantities and in good condition sometimes sell for fifty pes cent in advance of red ones.

Onions, unlike most other crops, may be raised on the same ground for an indefinite length of time, without any deterioration in quality or quantity, pro. vided the ground is in good heart. The writer know ground that has been used for upwards of thirty con. secutive years for this crop, and the last was as good, or better than the first.

It may not be amiss to remark here that skill in the onion business-and it is an important item-is only acquired, as in every other department of labor, by practice. Therefore it is better for a new beginner in the business to commence on a small scale. And let no one delude himself with the idea of becoming suddenly rich from raising onions. Patient, honest industey will here, as every where else, be rewarded, and when a good market is within a convenient distance, and the soil suits, pernaps no crop pays better then onions 
RaIsive ONION SaED.-As it is a law of nature that like prorluces like, it is of the utmost importance that great care should be taken to obtain seed that will produce the most perfect specimens of its kiud. This holds true in regard to onion seed, for it is a notonous fact, that this esculent has been improved in shape and color within a fow years, from a flat turnip-shape and pale red color, to nearly a round or spherical form, and a b ight clear red.

In saving onions for soed then, care shouid be taken to select those of the desired shape and color, and of medium size, or a little above it. The best time to do this is when they are pulled, as then the perfectly ripe ones are more easily distinguished, than when they are cured. Another advantage to be gained is, that tho earliest may be reserved, ir srder to get an earlier crop, if desired, the next year. Onions intended for sood should be set out abcut the middle of April, or at the usual time of sowing. The ground should be prepared in the same manner as for the regular crops, and then laid out in drills about three feet apart, and four inches deep. In these drills the onions are to be placed, four or five inches apart, covered with fine dirt and gently pressed down with the feet, or hand roller. As soon as they are well out of ground, they should be gone through with a hoe or cultivator, and the weeds kept down by occasionally hoeing the cround, and weeding, until the seed is ripe. The writer has found that diggnng a trench between the rows, either with a spads or hce, about tte time tas seed is in blossom, sua worising the dirt thus aug out around the onion stalks, is beneflcial. Care should de taken after the unions have olossomed, nor to inanale them, or disturb their roots.

The seed matures abuut the same nime shat. onione raised from the seed get ripe. The time for gathering is when the heads assume a brown color, and the balls begin to crack and show the seed. The heads should then be cut off and exposed to the sun on a blanket or floor, until the seed will readily shell; then by ruhbing with the hands, or tbreshing with a flail if a quantity is raised, the seed is made ready to bo passcid through a fanning-mill, or exposed to a winnowing process. After this is done, the seed should be putin a vessel of water, and only that which readily sinks a to be preserved. It is then dried in the sun for two or three days, and put a way in a Jag, in a dry, airy place, until wanted. Onion seed etculd never be trusted after it is two years old.

The price of seed varies as much as the price of the onions themselves, ranging from $\$ 1.00$ to $\$ 5.00$ per pound. The different varieties when planted for seed, should be put at considerable distance apart, as the seed readily mixes. From three to fire pounds of seed are usually raised from a bushel of onions.

No. II.

\section{BY JOHN H. SHERWOOD, FAIRFIELD CO., CT.}

The Ouion has become an important vegetable in our markets, and the demand is yearly increasing at prices which make their cultivation profitable. Large quantities of onions are produced in this vicinity, and I will offer a few remarks on their cultivation which I have derived from much experience and observation, trusting they may be of advantage to those who wish to cultivate them. Experience will be found the best teacher, but a few facts and general ideas put in print, will be a great help to new beginners.

THE Sorl most congenial to them is a strong damp loam, and I think the crop is generally larger where a small quantity of clay exists in the soil. I have known large crops on quite stiff clay soil when the land is well under-drained.

To have onions succeed well, the ground on which thej are planted should have been cultivated at least two years with some boed crops, and highly manured for tinose crops. Commencing with grass land, the flrst crop might be corn, next year potatoes, or what is better, carrots, as potatoes are apt to rot with higb manuring. My reason for cultivating two years before the onion crop, is, because the grasroots in the soil require that time to decay-besides, the soil is so loose, that worms are apt to injure the onions, if not destroy most of the crop.

The kind of onion usually grown here, is the red, and those are preferred which approach the nearest to a globe in shape. as the yield per acre is greater. The white, though better for the table, and command. ing near one third more in price, is but little cultivated, as the crup is seldom as large, and the care required in curing them, prevents their general cultivation. They are very liable to mildew and decay, which, be. ing conspicuous on their white skins, makes them les. salable than the stronger red skins

SEED. - Nothing is of more importance in securing a good crop of onions, than having fresh new seed of the right kind, as many fail when they depend on importer seed, or that which is raised wo know not where or how-raised to sell, probably. Many men in this vicinity loat their crop last year from this canse, the fault being entirely in the seed, as that raised by them. selves or neighbors, planted side by side, did well 
Thile seod obtained from a distance, in numerous intences, went to tops, or made "straight onions, as we call them.

Th grow goud seed, select the globe-shaped bulbs of grod size. In the fall put them in a dry cool place, but not where they will freeze much. Set them out as early as possible in spring, or as early in April as the ground can be worked. Set in goud garden-8oil, in rows thrte foet apart, and eight inches distant in the row $-c r$ to paricilarize, slightly ridge the land, and set lie oniuns in the furrows, about four inches below tho level, and as as they grow, keep entirely free frow weeds, and fill in the furrows from the ridge. The dis 6 helps to support them upright. Otherwise. as tho seed-balls gr.w heavy, the wind rocks them avour, and much of the seed is lost or injured by bisstung. The seed-balls should be carefully cut when beginning to brown, and spread thin to prevent beating.

When perfectly dry, thresh and winnow clean, then put into water. The good seed sinks, while the imperfect will float, and should be skimmed off and thrown away. Care must be tuken to dry thoroughly after removing it from the water. One bushel of good onions usually yields from three to five pounds of seed.

LAND intended for onions should be nearly level, to prevent the heavy rains from washing it after the seed is sown. The onion is a gross feeder, and requires \& liberal supply oi manure, say from sixteen to twenty loads, of fifty bushels each, well-rotted manure per acre. I prefer manure from the hog-pen, but where large quantities are grown, all kinds are used, first fermenting it to destroy foul seeds as much as possible, and fit it to mix with the soil more easily and evenly. A dressing of asnes is very advantageous to the crop.

To prepare the ground for onions, frst clear the surface of ull small stones above the size of a hen's eyg, put on the manure, spread anci plough to the depth of soven inches the first year. After that, plough somewhat deeper. The ploughing may be done in November, if you bave many to plant, and wish to get them in early. Let the ground lie in the furrow until spring, and then spread on at least one hundred bushels of ashes to the acre. If no ashes are used, apply from cwo to three hundred pounds of guano, and harrow with iron teeth, if the ground was ploughed in the fall; otherwise use a plank frame, or a plank with brush set in, which will leave the land smoother for the hand. rake. As the bush-harrow will need some welght, about that of a man, I usually ride on it, and by change of position can throw my weight wo as to fill up holes and leave the ground more evel,, which saves buad-labor. If you wish straight rows-which look snd work better-atretch a line across your tield to draw the seed-d-ill by, and by moving it up to the work, there will be no difficult- in keeping straight. twe seed-drills used about here are very simple in con- rows at a time, twelve inches aparh ar 1 one Lalf inch deep. These are covered by passing a boe backwarc over the drill, or by the hand-rake drawn carefully parallel with the rows, which is the quickest way, an it covers two rows at once. Four pounds of good seed are plenty for one acre. It should be planted as early in April as the ground will admit. Do not work it when wet, for it will be lumpy, and hard to cover the seed properly. When up enough to $8 e \theta$ the rows, hoe between them, with a hoe made expressly for that use. The blade of the hoe should be eight inches in length and oue and a half broad, with a long crocked shank. Next comes the weediug.

Have a small hoe made like the above, but one and a half inches in length, set in a handle six incbes long. With this in one band, get on your knees, and crawl over them, destroying all the weeds: for if not well done at this time, the work will be hard the next. Second hoeing and weeding the same as first, but can he done faster. About this time, say the first of June, sow broad cast one bushel of salt to the acre, such as is used for hay. This will prevent the cut worm which is sometimes troublesome, and the salt I think, is a help to the crop. I can not say too much about keeping the weeds out, for no crop suffers more from weeds than onions. Keep the weods out as long as you can creep over them. They usually require four hoeings and weedıngs, which will carry them into July. If there are weods, get them out, even if the bulbs have begun to swell; you can walk through them and pull them by hand. This is the time they are apt to be neglected, as the haying season claim all the help.

As they attain their growth, the tops loose their lively green color, grow weak above the bulb, and drop over. When they grow exactly right, they all fall down; and when about two thirds dry, they are fit to pull. This is done by hand, cleaning of all weeds, to prevent the seed ripening. Spread the onions to wilt from two to four days, then pile about three bushels in a heap to sweat. Let them stand in this way for some days or until the tops are dried away. They are now fit for marketing in small quantities.

If you wish to house them to keep. spread them again, and dry ; for if housed damp or green, they will grow and injure quickly. Great care is necessary to cure them properly. They should be dried until no juice will ooze from the tops when twisted by the hand. They will require turning two or more times tc bring them to this state, then cart them before the der falls at night. When in the house, they should har free circulation of air atout them, until freezin weather, and then be protected from extreme cold, though they bear some freezing, and do not generally injure if let alone until the frost is all out. If they are intended for market before December, almost any out-building with a good roof will make a storo-housa the more air sbout them the better. If the floor is 
tigsh put down scantling, and lay on a temporary low fllor for the onions, and if room is plenty, do rot put them over two feet thick. That I may be better anderstood, I will give a description of a fit place to store onions for fall and winter keeping. Yake a building with the top of the sills one foot from the ground, to affurd room for air to blow freely under a lootw floor, laid upon the sills. On the inside of the buildi. g, crib around with boards to the height you wish to make the pile, leaving a space of fifteen inches between them and the outside.

As the onions are put in, set a small bundle of straw on the end, about once in five feet, to act as a ventilator. When cold weather approaches, fill the space around the outside, with the onion-tops which are cut, or an equivalent, and bank around outside the building with litter of some kind. In this region near the shore, sea-weed is used to a good purpose, but coarse manure will do, having some place where the air can be let in in mild weather. Cover the top of the onions with dry litter, such as hay, cornstalks or the like If put up in good order, they wiil keep in this way, and perhaps bring price enough to pay the extra work.
In cutting off the tops, a pocket-knife is generally used. This work can be done at any time after they are housed, but those intended for keeping late in Spring will do better to remain in the tops until wanted for market. It is difficult to tell at what time they should be marketed, as the price varies with the seasous. The large quantities raised along the shore here, are sold in New-York, mostly by the barrel, sent in sloops sailing between the city and the different ports. They are sent as soon as they are large enough in the fall, and continued until late in spring. As a general rule, probably, it would be well to dispose of one half of the crop before the holidays, and look ont for the remainder.

Five hundred bushels per acre are a fair yield, but seven or eight hundred bushel are often raised. Usually the yield is less the first year or two; atter that, if weld manured, the crop is more certain and the land may be continued in onions year after year. I know o. ground that has proauced onions for forty years in succession, with only a rest of one or two years, and yielded well.

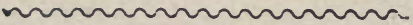

No. III.

\section{BY JONATHAN DENNIS, NEWPORT CO., R. I.}

THE Island of Rhode Island and the shores of Naragansett Bay, have long been celebrated for the raising of onions, particularly the town of Bristol, situated on the main land, twelve miles from the city of Prov. idence, and enjoying a fine harbor, from which large quantities of onions are annually shipped to NewYork and all the southern ports of the Union; but the largest trade perhaps, is carried on with the Island of Cuba, to which great quantities of potatoes, and onions, and other vegetables, are annually shipped, bringing sugar and molasses as return cargo.

Newport also carries on a corsiderable trade in onions $x d$ other vegetables, with the South.

Sorl. -The onion requires a rich soil, and if it is not natura'y so, it must be made so. by the addition of a liberas dressing of manure, otherwise it is of but little use to try to raise a crop of onions; black heavy soil and rather moist, or such as will not suffer from drouth, perhaps is the best; but almost any soil that will produce a good crop of Indian corn will answer if made rich enough. Old gardens that have been long culti. rated will generally raise a crop without much diffisulty, but new land, or land that has not been highly cultivated for a number of years, will not generally produce a full crop for the first year or two, owing, as !supnose, to the manure not besoming sufficiently in- corporated with the soil. Those not experienced in the raising of this crop should not be discouraged if they do not succeed the first year, for the onion, unlike most other crops, succeeds better the longer it is planted on the same ground, except in some instances af ter long planting in the same place, they seem to be. come diseased from some cause not well understood, when alternating with another crop for a year or two is said to remedy the evil. This disease shows itsell by the curling of the leaves and turning of a yellow sickly hue, and upon breaking the leaves they appeal to be filled with a kind of smut; hence the disorder is called the smut.

MANURE. - That from the hog-pen I consider the Dest, but barn or stable-manure will answer nearly as well on most soils; sea manure is considered excel. lent on our soils. The waters of Naragansett Bay produce large quantities of marine plants, which are washed on the shores and collected by the farmers, and composted in barn-yard and hog.pen, and produce a most valuable manure for this crop.

Large quantities of fish are taken in this bay, and when composted and mixed with barn or hog-yard manure, are much used for onions. Gaano does not seem to suit them as well as it does some other crops and I rocld not advise farmers to try to raise nnione 
with it alone. Wood ashes are an excellent manure on a.sy soll, and perhaps the greensand of New Jersey would answer, as they seem to require potash.

Preparation of the Soll-The manure should be spread twenty-five or thirty loads for two horses or one pair of oxen, or a cart-load of forty bushels to the acre, and ploughed in with a good even furrow. The depth will depend on the depth the soil has been previously cultivated. Tire whole should be thoroughIy turned over. covering the manure completely; and if the ground has not been highly manured previously, it should have a light dressing on top, of decomposed manure, or wood ashes. Then harrow the ground fine with a light harrow, and rake smooth and level, removing any coarse manure, stones, or lumps that may interfere with planting or hoeing. If you have a large bed, it saves labor to strike furrows through it, say a rod or more apart, before commencing to rake, into which all the lumps of manure and smali stones may be deposited and leveled over with the soil. Those places will bo found to produce as well or better than the rest of the pieces.

Plantivg.-Plant in hills with the rows twelve inches apart, and six inches between the hills. We use a machine that plants in hills, two rows at once, at the required distanco apart. Never plant them in drills if you can avoid it. If you have no machine that will plant in hills, I think you will save time in the after-cultivation by planting by hand. It is tedious work to weed a drill-row, but in hills you can do nost of the weeding with the hoe. Put from six to eight seeds in a hill if you wish to raise them of nearly uniform size for marketing by the bushel. With us, where most of the crop is bunched on straw, for the West-India and other foreign markets, we put from ten to twelve seeds in the hill, and we never thin them out They seldom all vegetate, and some will be cut up in hoeing, so that two thirds the number you plant will be all, perhaps, that will come to maturity. They require but slight covering, not exceeding one half or three quarters of an inch deep, pressing the earth down sightly upon the seed. Our machines are provided with a roller that does this. Onions will grow well very thick if provided with a sufficient quantity of manure.

VARIETIES. - The kind will depend altogether on the market you wish to supply. We raise the common red onion, beçuse it suits our market. Each one should consult the wants of his customers in this as in every other crop. The Yellow Danvers is a good sort for our home market. It is hardy, cooks white, and keeps well through the winter. The White Portugal is a delicate onion, and sells the highest in our home markets of any variety, but is a poor keeper for winter and spring use.

The red with us is livided into three sorts, as they are called, though in fact they are all one, namoly, the early, second early, and late, and ans producel by merely selecting the onions for seed. The early is a flat onion, sometimes even hollowed at the crown, the second early is full and round, and the late is some. what pointed at both ends. Therefore all you have to do to produce those varieties, is to select the flattest onions you can find, to raise your seed from, if you wish to raise early; the full round for the second early, and so on, and you can readily produce the sind you wish by a fow years' propagation in this way. Wo raise the second sort mostly because it produces well, and suits our market, though there are considerable quantities of the early variety raised for the early market, which do very well, although they do not produce as mucn, but bring a nigher price on accourt of being early. Be careful in purchasing seed to buy from those you can rely upon, as old seed is very un certain.

The potato-onion is largely raised by market-gardeners, to be pulled up when partly grown, and tied in bunches of six or more for the market. They are a valuable variety, being of mild flavor, and cook very white. They are propagated by sets and not by seed. A large bulb set out in spring will produce a number, some of good size, which may be pulled for market or the table, with several small ones, which may by set the next year, and which in turn produce one or two large ones. There are a great many raised from pips, as they are called, which are the very small onions lef from the main crop of the red variety, set out in spring similar to the potato-onion. They will incline to run to seed, and the seed-stalk must be broken off Be careful to break them below the large plsce on the stalk, and they will produce a good bulb for early use. Both the pips and potato-onion may be set thickly in drills, as early in spring as the state of the ground will admit of, and with a litle hoeing they will produce a good early crop. There is a variety called the top-onion, which produces the seed or set on the top, like the garlic; but they are not much grown, and with us are not considered worthy of cultivation.

HOEING.-Onions should be hoed as soon as the rows can be scen, and as often as the weeds show themselves. I consider it better to hce often, for you can hoe them twice over when they are not very weedy, in about the same time it would take to do it once if you let them get overrun with weeds; and then it is a long and tedious job to clear them out, besides injuring the crop in so doing. After tho second or third hoeing, when they have got a good start, carrots may be planted between the hills in two out of three rows, and so on, leaving one out of three for space to lay the onions to cure, and in this way a goor crop of carrots can be raised without injuring the onions but very little, if auy. Large quantities of car. rots are raised in this manner with us with very little expense. They will want one hoeing after harvestir o 
the ceions, to cloan out any weeds that may be still otanding on the ground. The carrots will grow rapidby till frost, and even after.

Ha RVESTINa. - The onions should be pulled as soon as the tops have mostly fallen, which shows maturity. Lay them is rows, two or three rows together, straight and evenly, uud when the tops are nearly dry. cut them off, leaviug about two inches of the stalk. Leave them to dry a few days longer if they are to be stored, or they may be marketed immediately. In topping, have the bottoms at the left hand, and the knife or shears (some use common sheep-shears) in the right, when, if they are laid evenly, you can take a number at on $\theta$ instead of taking each one singly, and boys that are used to it will top them very fast.

Bexching. - To bunch onions rapidly and handsome'y requires much practice, but some boys will make from three to four hundred bunches a day. It is done this: Take about two feet in length of the butt end of rye straw, and in size nearly as large as a broomstick when drawn together by the twine. Commence at the bottom, and wind common wrapping twine around it for three inclies, drawing it up tight, then put on a circle of four medium-sized onions to begin with, take a turn round the reck of these, draw them up snug to the straw, tying the next on the top of them As you proceed, press them down snug upon each other with the thumb of the left hand, and wind the twine once around to each onion, tapering them up from a good-sized one at the bottom, to the size of a large walnut at the top, and from ten to twelve in length. Keep the rows straight, and with a littlo practice, you car make a neat bunch that will suit, is many markets, better than loose onions, and also us: up and make salable the small-sized onions.

Au average crop with us may be stated at from fou: hundred to five hundred bushels per acre, though we sometimes get six hundred. The price varies from thir ty-five to fifty ceuts per bushel delivered at the landing on tide-water direct from the field. When the shippers pay from two to three dollars the hundred bunches, of three pounds to the buuch, for large quantities, taking the whole crop at once and directly from the field, it is considered a profitable crop. There is little done in the retail way, except for a few early cres in our home markets.

Storing.-Store your onions in a dry cool place, to keep through the winter. The garret is a good place for those who wish to keep a few for family use, cov. ering them witl some old cloth to prevent their thaw ing when once frozen. But if you wish to keep a large quantity, any out-building that is tolerahly tight, will answer by packing the sides with hay or straw, and covering the top with the same. The cellar, unless very dry, is not a good place to keep them, on acrount of their growing if kept too warm. A basement-story perhaps would answer if not too warm. They should not be moved while frozen, except you wish to conk them immediately.

I have written especially with regard to the onion as a field crop, for in this section they are raised as such, by farmers who cultivate quite large tracts, and in fields from one half-acre to three acres.

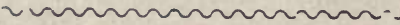

No. IV.

\section{BY D. C. REYNOLDS, CLINTON CO., PA.}

THE oniun tribu, consisting of the onion, leek, garlic, seeds alung the drills about three or four seeds to the and shallot, are all native of Easteru countries, but inch. they seem to be well adapted to certain portions of the Next, sift fine sandy earth over the seeds, and pat United States, and acquire considerable pungency of the surface even. Finally, scatter leached ashes over favor in this climate.

In order to be successful in growing the onion, the wil must be rich, light, and deep. and in a situation well expred to the suv. You must not think of sow. ung the serd until you have worked the bed well to the depth of eighteen inches, enriching it, and beating at flat and firm with a spade.

Some may suppose it early, but I alrays suw my onson seed sometime in March, not being at all particular as to the precise time of the month, or having any regard $w$, the superstition 80 prevalent in regard to signs. No gand gardener can dispense with the line: be will therefore scrutch drills by the line just deep nourh to be clearly seen and then distribute the the bed, evenly, to the depth of about one eighth of an inch. Be careful to allow no weeds to grow up and choke the young plants This is a very important precaution, as I think the shade caused by rank weeds is one of tha greatest causes of small (rops in this coun. try. As the onions grow, they must be thinned out; allowing alternately a space botween, fully equal to the breadth of the onion from bulb to bulb. There are some who prefer to 80 w onions broadcast, biut I am satisfied they lose more by their indolence than they gain in point of economy of time. After the onions have somewhat advanced, it will be beneficial to scatter common salt among them, the chemical propertie of the salt seem to case them to enlarge 
This is about as good a way to cuitivate the onton from the seed to the perfect large onion, as I have ever seen, or tried - and it is my custom to examine every new idea, or experiment, that comes before the public, with a view to a correct plan, not only with the onion, but all kinds of regetables. In September, the necks of the onions should be twisted, and after the leaves become yellow, take the crop up, and place the onions under a shed, exposed to sun and air until they are quite dry on the outside. Of the different kinds, I prefer the white, as not being so rank to the tiste, and we know they always bring a better price in the mrrket. Although I coufess to having been often disappointed in my experience with Patent Office seeds, owing to their age before they are placed in the ground, yet I can safely recommend the "white onion" obtained from England, as of superior quality both as regards size and taste.

Besides the onions raised from the seed, we can grow them so as to have a supply in July. The ground, in this case, must be prepared early as the weather will permit, ic February, and for seed take a number of those small bulbs that are always found in the beds just described, and which are no; above an inch broad. The bed being ready at the end of the first week, form it into squares on the surface by meaus of cross-strings At the places where the lines meet, press in an onion, one third of the onion being placed in the ground, so that the bulb will remain firm and erech After this is done, you will have a bed with the onions in squares, five or six inches apart. Now, the onion naturally furms its bulb the first year of its growth, and forms fower and seed in the second year. Of course, therefore, these small onions, being in their second year, will attempt to form flower and seed, and this must be prevented by plucking off the flower-head as swon as it makes its appeurance. A second attempt will be made, which must also bo preventr.d in the same way. Thus, the sap, which would otherwise have "run to seed," will be kept in the bulb, and by degrees two, three, or four medium-sized onions will be developed. These are to be taken in July or August, and dried under a she $\mathrm{d}$, as before directed.

A great amount of nonsense, in the shape of "experiments," has been given to the world on the subject of the onion: but as I have already remarked, give me a soil rjoh light, deep, and well exponsed to the sun, and is addition. $\mathrm{d} f \mathrm{w}$ busheis of leached ashes, and a reasonahle quantity of cominon salt, and I will show you a crup of onions equal tr anv ever produced by acy other mode
The onion is a plant whose roots foud upon uourish ment on or very near the surface-Lence deep somn and planting, as well as hoeing the earth around the plants, are to be avoided. In very hot weatner in summer, it may be necessary to water them - but do not carry this to extremes. The onion is a very hardy plant, and I bave frequently left bulbs in the groand ih. oughout the winter for the purpose of obtaining wn early mess on the dinner-table in spring.

These is another mode of raising the onion which I like very well, although requiring a greater length of time to devtlop. This is by sowing the seed, thickly in drills from three $w$ five inches apart, having prepared the ground in the same manner as above descrited, and reserving the leached ashes and salt for the second year. By this method, you procure a number of bunbels of small onions, which are to be kept over winter in a place dry, not two warm, and yet where they will not freeze. These must be planted as early as the spring weather will admit, in the second year, and the flower-shouts must be plucked off, as I have said in speaking of the early summer variety. They must be planted in the same way, in squares of five or six inches apart.

The onion has been too slightly cultivated. This is owing to the vulgar notion of its unpleasant smell. It is true, it is apt to affect the breath, so that one who has eaten of this really wholesome vegetable, will smell of it for many hours afterwards. But this should bo no reason for abandoning its use, as we can always 80 arrange our meal that it can be eaten when there is no risk of this sort.

The onion has been successfully used as a medicina particularly in croupy affections of children-both the expressed juice mixed with sugar, and in the form of a poultice to the chest and extremities It is stimulant, acts upon the kidneys, upon the bronchial tubee ald air-passages, and will excite irritation on the skin. If eaten in moderatiı, it increases the appetite and promotes digestion, and may be used as a condiment; but in large quantities it is apt to cause flatulence, gastric uneasiness, and febrile excitement. It may bo given with advantage in dropsy and gravel. If it to boiled, it loses its essential oil, and becomes a wholesome and harmless esculent. It may also be roastod and split, and applied with benetit to suppurating tumors. In fact, it is one of the most useful vegetables we possess, and deserves better treatment at the bands of man. 


\section{No. V.}

\section{BY STEPHEN HOYT \& SON, FAIRFIELD CO., CT.}

Son, is the first consideration in the culture of onions. To raise them successfully, it is important that this be right. The soil best adapted to them is a १AQFY, moist, (not wet,) rich loam, free from stone.

Fair crops of ovions may be raised upon a light dry soil in favorable seasons, but the tops are very liable to turn yellow just as they begin to bottom, and to die down before they are of much size, thus very materially diminishing the crop. The soil should be cultivated with some hoed crop, and no weeds allowed to ripen seed upon it fo: one or two years before planting with onions. After having decided upon the soil, the next thing is the

MANURE-Onions draw very heavily upon the soil, and to insure a large crop, manure should be applied liberally. No definite quantity can be recommended, as the condition of the land varies so much; but, as a general thing, there is more danger of not applying enough than too much. Stable or barn-yard manure when thoroughly decomposed, may be considered a very proper manure for onions. We have found ashes very beneficial, and have raised fine crops with no other manure. They should be composted with swamp-muck, using one load of ashes to ten or twelve of muck. Apply twenty-five or thirty loads to the acre-more would oe better. Fish composted with muck, makes a very superior manure for onions, not excellod if equalled by any other manure. Eight to ten thousand fish, (moss bunkers, properly composted, make a good dressing for an acre. We have used guano, and it makes วnions, like almost every thing else, grow, yet we are not in favor of its use, only when composted with muck, or mixed with good soil. If nothing else can be had, guano may be used with success, but should lay composted a few months before using. It is unnecessary to particularize the kinds of manure further. Any well-rotted manure may be used with advantage if applied in sufficient quantity.

Plodghing, Harrowing, Eto.-This we would recommend to be done as early in the spring as the ground will admit. First, plough deep, and harrow down. Then spread on the manure and plough in shallow, say four inches. If ashes are used, spread them upon the surface and harrow in. After the second ploughing, harrow again, and pick off the stones, if there are any; then roll, (this is vory important,) harrow olice more and rake off, so as to remove all stones, grasa roots, etc. It is very important to have the groand fine and clean before sowing, as much of the after-cultivation depends npon this.

SEED.-There is nothing, perhaps, in raising onions f more importance than the seed, which should be fitt to start with If the seed is poor and fails to come, or a part comes, it not only lessens the crop, bus is a source of much vexation. We have found it the most reliable course to raise our own seed. The best onions should be selected and put out as early as possible in the spring; in rows three feet apart, and six inches distant in the row. Hoe often to keep clean, and when the hulls begin to open, remove the hcads to some place under cover, where they may remain to be cleaned out at leisure. The seed may be loosened from the heads by threshing them with a flail, or by rubbing in the hands, and then run through a fanning-mill. If it is then put into a tub of water, the poor seed will fioat and may be removed from the sur face, leaving the good at the bottom, in a clean state, after which it should be taken out and dried. We have frequently bought seed, as those just com mencing the business have to do. In this case it should be tried before sowing. This may be done by placing some cotton thoroughly wet in a tumbler, sprinkling a few seeds over the surface of the cotton, and placing the tumbler in a warm place. In a few days the seed will germinate if it is good. It is im portant to have new seed, as old is very liable to fail. or if it does not, the sprout is more feoble and puny.

We prefer the red globe variety for general cultiva. tion, as they are bardy and yield better than any other. White onions sell for a large price, but they are more tender, and we have condemned them for general cultivation. We have had several trials with them, and found them to yield well; but they are very liable tc decay or become spotted; so as to injure their sale.

SOWING may be done with almost any seed-drill, but we generally use one made expressly for the purpose, sowing two rows at once, twelve inches apart. A boy follows behind, covering the seed with the nead of a rake. With this kind of machine, a man and boy will sow two acres per day. We have found four pounds of seed to the acre the proper quantity. The zeed should be sowed as early as the ground will admit.

HoEING AND WEEDING.-As soon as the onions are up so as to distinguish the rows, they should be hoed by a careful hand, using a hoe with a blade eight inches in length and two in width. These hoes may be obtained at most agricultural stores, and are preferred because they cover the onions much less than a common hoe. Repeat the hoeing again in a few days, and follow by weeding, using the greatest care to remove all the weeds, as the after-expense will depend much upon the first dressing-out. Never allow onions to suffer for the want of weeding, but clean as the weeds are coming up. If weeds are allowed to attain much size, they are very apt to take root again, етзџ 
when pulled out, and the patch will soon be overrun. Our rule is, to stir the ground often, and never let the onions suffer for want of weeding. By so doing they are dressed out quickly and at little expense. Continue to hoe and stir the ground until the bulbs are too large to work among without injuring them. Thinning is unnecessary when only the above quantity of seed is used.

Pullixg aNd Curiva.-As soon as the tops have died down, or nearly so, pull them. When onions do well, their tops will lop over just at the top of the onion, and gradually die away. The grower will mainly have to be his own judge when to pull. There are seasons, however, when a large proportion of the onions are inclined to run to scallions or large-necked bulbs, and a beginner may be at a loss what to do. Many remedies have been recommended to make onions bottom, but we have found them of but little 7se. Watch them closely, and after being satisfied that they are making no more bottoms, pull them notwithstanding the tops may be green, keeping the scal'ions (or unbottomed onions) hy themselves, as they will never cure sufficiently to be housed with the other mpions. We would here mention that it is our opinion that greer. or unfermented manures on ground that has zever raised onions, are very apt to produce the above results.

Having decided that tho onions are fit to gather, first pull six or eight rows, throwing them upon the unpulled ones to get a start. Then hoe over and rake off the strip pulled, to remove all weeds or grass, if any are growing. If there are no weeds, this will be annecessary. After having cleaned off a strip, pull six or eight rows more, throwing the onions together with those first pulled upon the strip hoed and raked off. Hoe and rake off as before, and so continue to pull and boe until the piece is finished, leaving the onions spread broadcast over the surface of the field. The scallions, if any, may be left to go out with the weeds or refuse. Let the onions remain in this situstion for two weeks or more, until well cured, that is, antil the tops have become thoroughly dry. They should then be turned over with a rake, as many of them will be imbedded into the ground more or less, gathering moisture. In a few hours after stirring, with a good sun, they will be fit for housing. It mat. ters not, however, if they remain in the fleld for - mcatb after pulling, or at least until freezing weather Ir fact, we prefer to have them remain out as long as it will snswer, as they are very apt to sweat, heat, and sprout when put in large quantities, if housed early, although ever so well cured, and it is quite as convenient to market them from the field. It is recommendod and practised by many to pile the onions as they are palled. We bave practised it, but prefer the method above described. When piled, they want more attention in curing, as they are very apt to bold moisture enough from rains to make them blacken, if not opened and stirred frequently.

Houswa. - It is highly important to have them stored in a suitable place. This needs to be dry, cool, and, when necessary, warm. We have housed them in the cellar, but find it too damp and warm. They are very liable to sprout and rot, and it is difficult to keep them until spring. This, however, depends much upon the dampness of the cellar. Perbaps as suitable a place as can be had, unless by constructing a house expressly for it, is the bay of a barn, using that portion only below the first beam or sill. A tight fmr shris be provided, and the sides lined with saw-dust, tanbark, turning-shavings, or something of the kind, to a thickness of six or eight inches. A door shsuld be made at each end, so that there may be a circulation of air, until compelled to close them by the severity of the weather. A place of this description wall hold several hundred busliels, and should contain one or two temporary partitions, running lengthwise, and as high as the onions. This prevents them from lying so compact, and tends to keep them from heating, sweating, etc. Sticks, boards, or any thing of the kind, placed in through them, answers a good purpose. As soon as freezing weather sets in, close the doors, and cover with straw. Those designed to be marketed before the severe cold weather comes on, may be put in any place under cover. Those designed fo: wintering should be put in with tops on, as they sprout much less. In fact it is better to top them as they are marketed, in all cases. Topping makes good wet-weather employment.

MARKETING. - The producer will bave to exercise his own judgment as to the proper season for marketing. For a number of years past they have brought the best price in the spring, yet there bave been springs when we have thrown away hundreds of bushels. This, however, seldom occurs. Where a person raises largely, it is necessary to commence marketing as soon as the onions are ripe enough to pull, in order to get them off in time. We have found it advisable to sell whenever they bricg a good paying price. They stould never be moved while frozen. If kept covered and undisturbed while frozen, the frost will leave them uninjured, unless it is too severe, and often repeated.

YreLd. - Much depends upon the soil and season for a large yield. The average crop is about five hundred bushels per acre. A large yield can not be expected in this section without having the soil of the proper texture and a heavy manuring. The more manure, the more onions. There is no difficulty in raising eight or nine hundred bushels per acre. The same ground may be used for many years in succession if well manured, and with better success than by changing every yent, or every few years. Pains should be taken to deetroy all weeds. so that none shall go to soed upon the 
grouna, and asso in making manure, that no seed may oo present in that. By so doing for a few years, onions may be raised with but little expense.

Experiunce is uecessary to raise onions successfully. Fe would not advise any person unacquainted with growng onions, to euter iuto it very largely at first, for it would very likely prove a failure. We have soserved several instances where individuals have commenced with a small patch, who have increased gradually until they have reaclod s1x, eight, or ver acres, while others commencing with one acre or more, were unsuccessful, and have abandoned the business. It can not be expected that from three to four hundred dollars per acre should be realized with. out considerable expense; and although we may read the various methods of others in regard to it, we are ill-prepared to go iuto the business of raising onions on a large scale without experience.

No. ví.

\section{BY ARTHUR C. TAYLOR, FAIRFIELD CO., CT.}

Trz first thing to look after is the seed. In selectng the onions to plaut for seed, choose those of a oright red color, of a medium size, with a smali top, (well dried down to where it joins the bulb,) in shape as near round as you car find. Round onions yield more per acre than flat ones. If your seed-onions are deeper than they are broad, your onions will be inclined to run to seallions, (unsaldble onions with thick green tops, ) a result much to be dreaded by the onionraiser. Plant your seed-ouions in drills, three feet apart, the onions four inches apart in the drills. Plant deep in the ground, and hoe the dirt up to the plants as they grow. In weeding, be careful not to rub the seed-stalks, as it will sometimes cause the seed to blast. When the stalks have nearly all turned yellow, cut off the seed-balls, and dry them on a roof or garret floor. When dry, clean the seed, ready for sowing in the sprinz.

In choosing the ground, a ievel piece is preferable to side-hill, on account of its being less liable to be washed by spring rains. The soil should be deep and ricl, nej' ner too wet nor too dry, (of the two rather moist.) Onlike most other crops, onions may be planted on t' $\theta$ same ground for a great number of years, and still $r$ ing good crops.

$Y$ snure very highly, stable-manure, ground bones, $a^{\circ} .38$, and guano are all very good. Stable-manure jould be ploughed in; be careful to turn it all under. Bunes or ashes may be harrowed in after the ground n ploughed. Guano should he raked in after the harrowing is done. Guano does well with other manure. It gives the young plants a good start tarly in the reaoon. The ground should be ploughed deep. It may be done either in the fall or in the spring. Fall ploughing is preferred by many, as it helps on the spring work, and gives a chance to get the seed in the ground early. which is a great advantage. As 800 as the ground is free from frost, and dry enough to pulverize the lumps, barrow it well, first with the tooth, then with a nice oren brush-harrow. After the harrowing has been thoroughly done. use the hand rake untll your ground is free from lumps and stones. Be careful to pick up all the stones. The ground is nor ready for the seed. Sow in drills one foot apart: gauge your machine tc sow about four pounds per acre. If the ground is in good order, and you are sure your seed is all good, a little less than four p:unds will do per acre. Cover the seed by pushing the head of a rake or the back of a corn-hoe along the drills. If the rows are made very straight, it will save time in cultivating.

Nothing more is to be done until the onions are up enough to see the rows. Then go through with a light onion-hoe, stirring the ground between the rows. As soon as the onions are all up, put in the boys witb weeders, to take out the weeds which the hoes have left. The weeders are little hoes, two inches wide by one inch deep, with a short bandle. Boys soon be come very handy at this work, and are better than mer at the business. All we have to do now, is to keep free from weeds by hoeing and weeding until pulling-time, which is generally in September. When tho tops have nearly all fallen down, and about half of them are dry, they are fit to pull. Leave them on the ground after they are pulled until the tops are all dry, then store them in a dry place. Onions will look brighter if lieaped up soon after pulling, and left in heaps to cure.

Much care should be used in curing white onions, as the sale of them is injured by having the skins mil. dewed. They should be pulled earlier than red onions. A good plan is to carry them ic, soon after pulling, and dry them by spreadiug our win in lofts.

An importaut item after the onion crop is raised, is to have it well housed. Onions will keep best on a floor where the air can circulate over and under them. They should be kept cool, but must not be allowed to freeze much. Otiions for sted should be put in the cellar when the weather becomes cold, as the yiell of seed. will be small if the onions have been touched with frost. On a good piese of ground, six hundred bushels of onions can be raised to the acre, wbich at 50 cents per bushel, will bring $\$ 300$ from one sere of ground. 
If the planting of onions for seed has been neglect- $\int$ onions, than to get a supply from seed stot as where ed, great care sbould be taken in procuring seed. It you know nothing about the quality of the onion us better to give a large price for seed from selected / planted.

\section{No. VII.}

\section{BY DAVID H. SHERWOOD, FAIRFIELD CO., CT.}

RaIsure Serd.-Most people are aware that the great onion crop of the country is raised from the black soed. There has been a great change in the shape of the onion within a few years. They were formerly quite flat, but now the best are as far through from the top to the root as the other way. Therefore select the very best for seed, those that are as near round as passible, solid and smooth. These should be kept through the winter in a dry place, where the thermo. meter will not fall below $20^{\circ}$.

As soon as the frost is out of the ground in the spring, it should bo well manured and ploughed deep. Dig trenches thre feet apart and five inches deep. Set your oxions in the bottom of these drills about six inches apart. As they grow up, fill the trenches with dirt, and the stalks will not fall down, which is apt to blast tho seed. Keep clear from weeds until they blossom, after which do not disturb them. When the stalk below the seed-ball turns yellowish, and the seed-husks begin to open, cut off the seedballs and spread them thinly on a tight floor, stirring them oncy in three days; or, what is better, spread them on a lattice over a tight floor, as they will then bave the air around them, which is very essential, as they are apt to mildew. They should remain in this way for several weeks, until they will shell easy. After the chatf is blown out, pour the seed into water; throw away that which floats, and dry the remainder in the sun for three or four days; after which put in coarse tags, and hang where it will have plenty of air, as I know of no seed that is more likely to chit than onion-seed.

Preparation of the Ground for the reception of the seed, is the next thing of importance. I have seen good onions on reclaimed bog swamp, also on reclaimed swamp with a clay sub-soil, but I think the best ground for the purpose is a dry loam. It should first be in hoed crops three or four years, and all weeds kept from going to seed. Clear your ground hom all rubbish, stones, etc., in the fall, and, if possible, put on twenty loads, of fifty bushel each, of fine, well-rothed manure to the acre, and plough it in before winter. If thus treated in the fall, you can sow the seed in the spring much earlier and easier than if ploughed in the spring. But as many are apt to put off until w-morrow what should be done to-day, I will say, manure your ground in the spring as soon as it is arr enough to work, ploughing it in at once, as fast as it can be harrowed, raked, and sowed, as it is apt to become lumpy if allowed to lay in the sun after ploughing. Never use a tooth-harrow, as it will draw out the manure. I smooth the ground as follows: Take a plank eight feet long, one foot wide, and three inches thick. Through this, bore four holes, and insert four sticks, four feet long and three inches square. On the under-side of these sticks, fasten boards. The front plank standing edgewise as it moves along, will level the furrows, while the boards behind will smooth them. Wood ashes, at the rate of from one to two hundred bushels to the acre, harrowed in, will pay double their cost ir most cases. After you have leveled and smoothe $t$ your ground as much as con. venient with your team and leveler, use the hand. rake, leaving the surface as fine and even as possible.

In order to have your rows straight, draw a line across the fleld. Draw the planting-machine by the line. These machines for planting, which cost about five dollars, plant two drills at a time, one foot apart, and about half an inch deep. I use four pounds of seed to the acre, and cover by drawing a hand-rake lengthwise over the drills. The usual time of sowing here in the southern part of Connecticut, is from the first to the fifteenth of April. A hand-roller drawn over the ground after planting, will help the seed to germinate.

About two weeks is required to bring up the seed, and they should be hoed as soon as the rows can be seen, which will generally be the latter part of May. The most convenient hoe which I have seen for this purpose, is eight inches long and one and a half wide, inserted in a handle six feet long. Much depends upon how the hoo stands, about its working easy. If made right, the dirt will slide over it. After the weeds that are cut up by the hoe, have had time to die, they should be goue over carefully one row at a time, cutting and pulling every weed from the row. The most con verient way for doing this, is to crawl on your knees with a small hoe in one band, to cut where there is room, and pull with the other hand. The hoe for this purpose should be about three inches long, three fourths of an inch wide, inserted in a handle eight inches long.

From this time they should be kept perfectly free from weeds; to do this, they will require going over from three to five times, or once in two weeks; but as to this, there can be no rule given, as much depende upon the soil, the kind of manure weather. ete 
It is much easier to keep them clean by going over them often, than to put it off too long; besides, weeds ahado the ground and imporerish the soil. There should be no trees to shade the onions, as they will bardly grow in sight of one.

If the onions grow well, the tops will fall down before they are done growing; at other times they will stand stiff and never fall. If they fall down, they are fit to pull when about three fourths of the tops are dead, which is generaliy the last of August or the fore part of September. The sooner they are pulled atter they are fit, the better they will keep, and the brighter they will look. Commence, by pulling a few rows, and iay them one side. Hoe up the weeds and rake them off, then pull the next rows, and hoe off the weeds as before. Continue thus through the field. Pull with your hands, and lay them over carefully. If the weather is good, after they have lain spread for three or four days, pile them up, putting about three bushels in a pile in the form of a pyramid. Let them stand in this way from two to four weeks, or until the tops are all dead, and if there should be heavy rains during the time, the piles should be opened on a fair day, and piled again. Piling them up causes them to sweat, and they are then less likely to sweat after carrying in. After they are properly cured, open the piles on a drying day, and they will generally be fit to put in the day following. Never cart them until they are perfectly dry and dusty, and it should be done between 11 A.M. and 4 P.M. One half the secret of their keeping well, is in carting them when perfectly dry.

If they are to be disposed of before cold weather, they can be kept in any dry place where they will have air. The best place is on a loose floor, where the air will draw under them. If they are to be kept through the winter, have a tight floor, which the frost can not get under. On this lay scantling, upon which lay narrow boards, with cracks between them. Board up around the outside, leaving a space of one foot between them and the ontside partition. Arranged in this way, you have a free circulation of air all around them. When the thermometer sinks to $20^{\circ}$, fill the space around the outside with sea-weed, onion-tops, or someching of the kind, which easily stops the circulation of air. They can be put in such a place three feet deep, with hay, cornstalks, or something of the kind, two feet thick over them, and they will come out good in the spring. Before sending to market, cut the top one inch from the onion. If they get frozen, let them remain still and covered until thawed. Always handle them as carefully as you would apples, as a slight bruise will cause them to mould and rot.

The expense of an acre of onions with me is ahout as follows:

20 loads of manurg at $\$ 1.50 \ldots \ldots \ldots \ldots \ldots 37.00$

Carting, turning, spreading, etc..........6.08

100 bushels ashes, at $17 \mathrm{cts} . \ldots \ldots \ldots \ldots . . .17 .00$

Ploughing and harrowing, ...............00

Raking and sowing,.................4.00

$4 \mathrm{lbs}$. of seed, at $\$ 1, \ldots \ldots \ldots \ldots \ldots \ldots \ldots, \ldots \ldots$

Hoeing four times, 6 days, .............. 6.00

Weeding four times, 24 days, ............20.00

Pulling and piling, 12 days, ..........10.00

Drawing in with team, two days, .........6.00

Topping 500 bushels, at 2 ets.,..........10.00

Marketing, ......................... 8.00

Interest on land, ..............12.00

Tntal, ......\$137.00

A crop of onions will vary from 200 to 800 bushels to the acre, according to the state of the soil, manure, the care taken of them, etc. The price also varies from 10 cts. to $\$ 1$ per bushel.

The red globe onion is the variety generally raised for market, as it yields more than other varieties, and keeps better. The silver-skin onion brings the highest price, but is very apt to mould and rot before winter. Some may think, I have been very particular in the above description, but after they have had ten years' experience, they will find there is yet something to be learned. If you are too proud to go on your knees, or have not the patience to spend much time on a small place, or have not enough perseverance to do the same thing over and over again, you had better sell your seed, and sow your ground to buckwheat.

Onions are a crop which generally pay a large pro. fit, but sometimes the neglect of a fow days will spoil it. The same piece may be planted year after year with success. The weeding, pullirg, and topping can be done by faithful boys as we'l as by men.

It is estimated that from the towns of Fairfield and Westport there were sent to market last year, not far from 200,000 (two hundred thousanä) bushela 
No. VIII.

\section{BY G. I. MILLER, NIAGARA, CANADA WEST.}

Ir us sto greatest importance in growing onions to bave the right kind of soil, and that in the highest state of cultivation. In my opinion, a light sandy soil, well drained for all seasons, is preferable. Onions also can be raised to great advantage on black loam or light clay soil, providing the seasons are not too dry.

To prepare the ground, I would recommend a piece that has been planted with potatoes, manured with rotten horse-stable mannre, at the rate of about fifty loads per acre. As soon as the potatoes have been taken from the ground, plough about seven inches deep, letting it lie until the first of April, or as soon as the ground will admit of being worked, then adding about ten loads of hog-manure, well spread over the surface, and plough under from fivo to six inches deep, after which spread a few bushels of hen-manure, and then harrow the ground until it is well pulverized. The land is now ready to sow, for the earlier the seed is sown, the better the onions will be.

Testing the seed can bo done by cutting two sods from the ground, and pouring boiling water over them, letting the water drain well off, then placing the seed between the sods, and laying them under the stove for about two days, when the sced, if good, will sprout. I would recommend the large red globe onion as being the best variety for market.

The seed should be sown by a seed-drill, eighteen inches apart, in rows lengthwise of the land, at the rate of about three to three and a half pounds of seed per acre, leaving a space of three feet in the dead fur- rows for weeds, etc. It is necessary, as soon as tho rows can be plainly seen, to go through them with the hoe, leaving the ground as level as possible, and at the expiration of eight or ten days, go through them again, weeding, and thinning them from one to two inches apart; after which it will be necessary to apply the hoe every two weeks, always bearing in mind, that the oftener the ground is stirred, the greater will be the produce.

After the tops are dropped down and withered, then pull them at once, for if left in the above condition, they will take the second growth, which will injure the quality materially.

After they are pulled up, let them lay on the ground for a few days to dry, then top them with a sharp knife, taking care before doing this, that the onions are perfectly dry; after which, spread them thin, in a dry, cool place, and then you have them ready for the market.

It is advantageous to grow them on the same piece of ground for five or six years, adding a little manure every spring before ploughing.

Onions raised by this method will produce from seren to nine handred bushels per acre, on a light, sandy soil. Onions raised on the aforesaid plan have taken the first prizes for the last six years at our county and township shows, and the first prize at the Provin cial Agriculture Show, held at Toronto, Canada West

No. IX.

\section{BY ठ. E. DODGE, CHATAUQUE CO., N. Y.}

SEED.-To cultivate onions successfully, and with. out failures, care is necessary in selecting and raising seed. Seed should never be sown when over two years old. Onions, intended for seed, should be carefully selected, choosing the thickest and the most perfectly round, of medium size, and the brightest colors of the kind. These should be stored through the winter, or from December until the opening of spring. dt the earliest yossible moment, they should be set in furrows opened with the plough, three feet apart, and four inches in the rows. None but fine, well-pulverized land, should $b_{3}$ used for raising onion-seed. Cover two inenes deep. Aroid putting on any lumps or otones, as these, whenever they fall upon the onions, retard their coming up, and consequentiy make an on even harvest. All weeds must be kept down wilh the cultivator and hand-hoe, until tho seod matures, which will be about the last of Augasu, or the irst of September-never later than the sialu of Septrm. ber in this latitude. Their matun og way be easily known by the cracking of the ballis hs soon as the balls commence cracking, the heads, snould be clipped, leaving six or eight inches of the 8 dilk adhering to the head. The juice or sap which the stalk contains, ma. tures more perfect seed than when clipped short. The mode of cutting, is to take a common wooden pail is the left hand, and a sharp knife in the otiner, holding the blade parallel with the thumb. Slio the stalk bo 
tween the thumb and knife, at the same tnme swing up the pail to the standing stalk, and a slight draw with the right hand severs the head from the stalk, whinh falls into the pail, with all loose seed which would otherwise be lost. The pails, as they become full, are smptied into bags, and taken to the drying-barn. It is eot an extraordinary day's work for a man to cut ten bushels soed per day.

Drying the seed requires some care, and neglect in his branch is the cause of great loss by failures in the germination of the seed. Onion-seed, to be cured properly, and insure entire success in germination, should be dried in the shade, spread upon a smooth level Ioor, and not more than three inches thick. It should be turned twice every day, until perfectly dry. The first quality of seed is obtained from that which shells while turning; that which remains, and has to be threshed from the balls, being light, and of inferior quality.

Sorr. - That best adapted to the growth of onions is a deep mellow loam, resting on a dry, porous sub-soil. Although a vegetable of very shallow root, yet the onion delights in a deep, finely-pulverized soil. Cold, wet clay-sand seldom produces good crops, unless thoroughly underdrained, and otherwise mechanically prepared.

Preparation of the Ground. - Soil, containing the natural requisites, namely, dry, mellow, and fertile, should be ploughed in the fall, previous to sowing the crop. Twenty loads, of one cord each, of well-rotted mesure, prepared by shoveling over two or three times the summer previous, should be spread upon each acre. At each turning, put the outside of the heap into the middle of the pile, thus destroying thousands of weedseeds that would otherwise grow, causing much extra labor to eralicate them. The manure thus prepared is spread evenly upon the ground, and turned under with the plough from five to six inches deep, and thus remains til. spring, leaving the frost to pulverize the surface, and destrny all insects whose winter-quarters have. been made beneath the surface, and whose eggs and larvæ can not stand the severity of our winters, when exposed to the weather from November till April.

As soon in the spring as the weather and the soil will permit, the bed should be cross-ploughed, leaving the furrows upon edge as much as possible, so that a harrowing will mix the manure with the soil. It should be harrowed across the furrows, and raked iengthwise of them by hand.

Planting.-Draw a line at one side of the bed, and prepare a marker by taking a piece of scantling four by four, or any other convenient size, and bore four inchholes, trvelve inches apart. In these insert four pins for teeth, and make a hole in the middle of the piece, at right angles to the teeth, for a handle. With this, draw marks parallel with the line, and the ground is ready for sowing. Sow at the rate of four pounds seed to th a scra, with a seed-drill, being careful to gange the drill not to sow over that quantity, All over thrm increases the labor of thinning.

If the weather has the appearance of being dry, is would be well to roll, after sowing, with a hand-roller, but this is seldom required, as the rolle upon the drill usually presses the ground sufficiently for the germina tion of the seed.

CuLtuRE. - As soon as the onions make their ar. pearance above the ground, sufficient to distinguish the rows, they should be carefully dressed through with the scuffle-hoe, to destroy all young weeds that may be starting, and greatly facilitate the first hoeing and weeding, which should be done when the plants are about four inches high. Procrastination here pays heavy interest on the wrong side. Thin to three inches in the row diagonally thus: 3 in 3 in . Great results are frequently obtained by sowing broadcast at the weeding, when the ground is in a fresh state, three parts wood ashes, two parts fine dry pulverized hen-manure, and one part plaster, at the rate of three bushels to the acre.

The only sure road to success with this crop is clean cultivation, annual manuring, and careful attention during their growth. With these requisites, onions can be grown on land year after year. The writer of this, last year (1858) raised over five hundred bushels to the acre on land that had had no other crop upon it for over a quarter of a century, and by actual experiments finds that it produces better onious, and is easier tilled, in consequence of its being kept free from weeds year after year, and the onions are less liable to run to scallions. In this particular they are an excep. tion to any other crop, as all other crops are benefited by rotation.

As a market vegetable, the onion is one of the easiest grown; its plump, firm flesh is not liable to injury from bruises, as many other vegetables; its keeping qualities and hardiness to frost, render it a vegetable of the first importance for distant markets.

The onion is hardy in its nature, standing well the late frosts of spring and the early frosts of autumn, and the best results are obtained from the earliest sow. ing; in fact, this is almost indispensable to obtain a large crop, although there may be certain seasons in which a late crop may do well; but it is nct safe tc defer sowing later than the twentieth of April. The last of March, or the first of April would be preferred, if the ground was in the proper condition. No time should be lost upon the opening of spring until the seed is in. A little snow, or a few frosty.nights, will not injure it. With proper attention, and large drafts upon the bank of muck and manure, a few acres of onions will increase the deposits at the Bank of Exchange a large per centage in a few years, as I shall attempt to show in the following calculation, taking low market prices, and a bigh estimate on labor, and hardy an average per acre, say four hundred bushels . 
2 days' ploughing and dragging,

$\$ 4.00$

10 " raking and sowing,

30.00

20 " weeding and thinning, first time, 20.00

15 " " " second time, 15.00

8 " hoeing, last time,

8.00

20 " harresting and housing,

20.00

4 pounds seed,

20 loads of manure,

3 bushels top-dressing,

20.00

Interest on land,

Total,

$\$ 112.25$

400 bushels, at 50 cents,

200.00

Net profit per acre,

$\$ 87.75$

HARVESTING onions is not so laborious as many other kinds of vegetables; their maturity being earlier in the season, those engaged in their culture are not axposed to the late cold autumn winds, as they would se with a crop of beets, carrots, or turnips. The most expeditious mode of harvesting is to dig them with the common hand-boe, running one corner of the hoe under the row, giving it a long draw, taking about four rows at a time, digging over some ten or twelve feet; then, with the back of the hoe, shove them up three or four feet, and hoe the ground level, and spread the ouions upon this hoed space.

When treated in this way, they should lie from three to four weeks, or until perfectly dry. They shuuld then be picked from the bed, and carted to the barn, or some building where they will not be exposed to storms. and kept upon a floor, as they will soon Injure if piled in large heaps upon the ground, in consequence of the dampness which they draw from the earth. If properly dried, and secured from damp, they will keep for months in this condition, without any further trouble. They are liable to grow when damp, so that it is important that the cultivator see that this part of the work be conducted thoroughly and carefully.

MARKetiNa.-Onions are principally sold by the bushel, and by the string. If intended to market by the bushel, the tops should be cut elose and smooth, and all loose skin removed, to give them a bright, plump aprearance. If for home market, they may be put in bags, or hauled by the wagon-load, avoiding rough handling as far as may be. If for a distant market, barrels are the most convenient mode of packng. Fill them with the onions, packing tight, that that there be no shaking, and head strongly. Packed in this way, and perfectly dry, they will go thousands of miles by railroad or ship, and open fresh and sound.

Those intonded for strings should have two inches of the top left upon the onion. Thio strings are made by taking a few straws, (rye straw is best,) and with a piece of wrapping twine, commence at the butt end of the straw to wind, and at every two or three turns add sn onion, onding at the top. This sosures it firmly, and brings its broad, flat base upmes $t$ s = outside of the string. The largest shuuld be tied upor the bottom o the string, gradually diminishing in size, until th smallest are tied upon the top. This gives the strin a conical form, and a neat and tidy appearance, who arranged for sale.

Preservation. - Keeping through the winter, witt out injury from frosts, or loss from heating and grow ing, requires care and experience, and various method are adopted to aroid these results. They are baried i large ricks upou the ground, and covered with a heav coat of straw and a light coat of earth. Ttey are als tied upon strings, and hung upon the beams in th cellar or warm garret, or spread thinly upon shelves 1 the cellar Some pack in boxes or barrels, encase with several thicknesses of paper, and leave them i an out-building. All these have been practised wit varied success. The most popular mode, and the cn which has given the most satisfactory results, is spread straw, threshed with a flail, to the depth iwelve to eighteen inches upon the barn-floor, scaffolc or garret; upon this, spread the onious from six to te inches thick, and cover with straw eighteen inches t two feet, laying on old pieces of boards or rails to con press the straw. Treated in this way, if at a sufficien depth from frost, they are not affected by the change of temperature, and keep in fine condition till the fir: of May.

Onions are propagated from seed, sets, and mult pliers, or potatoe-onions. The universal mode of pr pagation at the South and West is from sets, whic are obtained by sowing the seed very thickly, broac cast or in drills, and when they obtain the size of filbert, pull them, and dry upon the ground in the sut These are kept till the following spring, and set b hand. They make a quick, strong growtl, and produc fine onions. Multipliers are a variety that produc large and small bulbs alternately, the large prodncin several small ones the first year, and theee small gir ing large the next year. These may be recommende as a small early crop for family use, and early hom market, but not as a main crop, the increase of marike able onions over the seed being too small. Of all th various modes of propagation, sowing the seed for main crop deserves first rank ; it cheapness, comparo with other modes, and the facility with which it sowed, the early season when it may be gathercd ir and the superior fine bulbs which it produces, recom mend it to general use. But whatever the mode c propagation, the cultivator can not expect remunerativ crops, unless he bestows careful attention to the selec tion of seod, the eradication of weeds during th period of their growth. annual application of well-com posted manure, and in large guantities, and the Larvest ing, securing. and marketing at the proper time. Wit. careful attention to these, and a naturally dry, fertil soil, onions may be grown, with large profits upon thr capital $\mathrm{i}$ =rested. 
No. $\mathbf{x}$.

\section{BY W. R. BUNNELL, BRIDGEPORT, FAIRFIELD C0., CT}

Kinds-The thick or globular deep-red onion, known as the Wethersfleld Large Red, is the kind generally grown in Fairfield county, Ct. It grows to a good size when thinly sown on good ground, yields well, is of a beautiful color and shape, tender in cooking, keeps well, and is very salable in New-York market, for use or shipping. Also a yellow onion, (generally called and sold for white, ) of nearly the same shape and qualities as the red, supposed to be the Danvers, which sells in the same market for one to two shillings a barrel more than the Reds, but does not generally yield so well.

SEED.- All seed should be raised from good-shaped if not large bulbs, to avoid scallions, (thick-necks or green onions;) should be water-cleaned and kept very dry, and though generally preferred only one year old, will succeed nearly as well after the second, or even third year, if it has been kept in a Grry place, but seed more than one year old sells at only half-price. Bought seed should alvays be put into water and stirred for a short time, and that which does not sink in fifteen minutes, may be considered worthless or unreliable.

SolL.-Any good garden soil, from a clay-loam to even quite a gravelly loam, say of one half mixture, is suitable. In a dry season the first will yield best, and n a wet one the last-a medium may ioe best.

Exposura - The best is a dry level, or a slight inslination to any point of the compass but the north. It should never incline over four inches to the rod, to prevent the rains from washing away the soil with the seeds or young plants. An inclination of one to two feet to the rod is sometimes seen. The plants on sidehills, after they get well rooted, do not suffer from the washing away of the soil, but those buried by the washed soil are injured; therefore if possible avoid ateep sido-hills and hollows, especially the latter, where water can stand after rains, which is most injurious of all.

MaNURE.-No fresh yard-manure should be used, as it is apt to be full of soeds, which will greatly increase the labor of tending, and the straw will be in the way of ploughing, raking, and hoeing. Night-soil or hogmanure is preferred. If barnyard manure is used, it should be thrown into heaps before the first of March, to kill the seeds and ripen for use by heating, or it may be carried out to the fleld and each load be heaped by itself, and tho earth around thrown upon them as soon as it thaws, to the depth of three or more inches, to keep off the cold winds, and preserve their moisture, and raise the heat high enough to vegetate the seeds. Turning, or well shaking up, putting the outside to the aiddle a week or two before using, will still further im- portion to that and the quality; it should be from forty to sixty or more ox-cart loads to the acre, and twelve to fifty bushels of leached ashes harrowed or raked in, or sowed on the rows after weeding.

Plodghnvg. - So soon as the ground is dry, have the manure on the field. First hoe it over, to cut up all grass, weeds, and roots, and rake them off; for if ploughed under, they will be a great plague. Then if the heaps of manure were covered with earth, hoe it off as they are wanted, and return it to the hollowe to level the ground, and spread it just fast enough to feed the plough, breaking it fine; then rake or scrape it with a dung-fork, into the furrow, to be covered in the next bout. Once ploughing is sufficient, if well done. $\Lambda$ second would throw out the manure. Im. mediately after ploughing, if your quantity of manure was not sufficient, strew any special manures, as poudrette, guano, superphosphate, Done-dust-probalily. the best of all, etc., to make up the deficiency. If the ground is lumpy, barrow lengtliwise first, and finish off by going over with the back of the harrow down, of with a brush harrow, (see Agriculturist, 1858, pago 108.) Then proceed to rake off all the storss and rubbish, and to even the surface. If the soil is mellow after ploughing, harrowing may be omitted. Many simply scatter short fresh manure, plough once, and rake down, drill and sow; but it is a miserable way, making extra work in weeding, and producing a lighter crop.

SowING.-This is cheapest and quickest done with a machine, called an onion-sower, which sows two rows at once, one foot apart, and costs about $\$ 5$, and is to be found at the agricultural stores. It must be regulated on a floor or board, to sow the seed to average $\frac{1}{4}$ to $\frac{8}{8}$ of an inch apart, which will be about 4 lbs. to the acre-3 $3 \frac{1}{2}$ to 4 is the usual quantity for a crop which is not to be thinned out. The machine does not cover the seed. This is done by ürawing the back of a hay-rake lengthwise over one ar two rows at a time. Any special manures may be scattered with great advantage upon the seed in the drills before covering. Make the drills about $\frac{8}{4}$ of an inch deep when open. But many prefer the old way of sowing by hand, and make a drill-rake with a head three feet four inches long, of three or four inches scantling, with three teeth fifteen inches long, pointed, and one foot apart, with a short curved handle four to five feet long Starting with a line for a guide, (which must also be used with the machine,) and afterwards following the ast drill with one tooth, and sow by hand, from a small cup, distributing the seed with the thumb and fngers at the same distances as stated for the mackine, 
precess In either case it should be most carefully and regularly done, and on a still day, or the wind will scatter it heyond the drills. The straighter and nar. rower tbe peed is sown in the drills, the narrower will be the sprace left to weed after hoeing. Radishes or soine quick-growiog seed may be sowed thinly, one or two eneds to a fort, to direct in hoeing the first time, as the onion tope are so fine they can scarcely be seen, excepting when the dew is on. The radishes may be suffered to grow, and be gathered for market.

HOELVG. - The first hoeing should be commenced when the rows can first be distinguished, with a hoe eight inches long, made by cutting off the back of an old grass-scythe, flattening the blade, and punching a small bole within thro fourths of an inch from each end, without beating in, to which a forked brace with goose-necks must be rivetel through the goose-heads, to attach it to a light, long bandle, usually that of a hay-rake. The beveled edge of the plate should be down, and the heads of the livets sunk. With this hoe proceed to scrape once in the middle between the rows, with a reach of two feet or sore, barely shaving off the weeds without breaking through the crust, carrying along one or more spaces. Keep the hoe in good order by rubbing on a flat stone, o: grinding, and if it clogs, which it will do on new-pluugled ground for two or three years from the sod, push it along on the ground as you step forward, or clean with a stick. The same process, which is light work, and quickly done, may be repeated with advantage within a week, out in a fortnight trom first hoeing, or less, according to the size of the weeds, hoe again, only breaking up the crust, say about half an inch deep, loosening but not moving the earth out of place, in the middle of the Bpaces as before, or, which is better, with two strokes, one close to each row, making nearly a double hoeing, which, if the rows can be distinctiy or readily seen, is the best manner for the first hoeing.

WEEDING. - The weeders, upon their hands and knees, should follow close upon the last hoeing, with onionweeders, made from table knives by breaking off the blades to two or two and a half inches from the handles, and heating the end to bend it a little to one side, so as to fit it to the curve of the thumb, and cooling it immediately, to return its temper. The back should then be gtound to an edge, and the corners rounded, 80 as to work it in either hand. The weeds should be cut off below the crowns of their roots, say half an inch under ground, or, which is better, loosen the grouud two inches deep on each side of tho row, by drawing the knife or weeder, thrust into the ground to the handle, and turned a little sideways in the hand, at a steep angle towards and on one side of the row and two inehes from it, and then by changing hands, on the other, when, if properly done, the ground will be loosened, so that the wecds can easily be scraped or nulled out with their roots, and then the earth should be pressed back upon the roots of tie onions by the palms of the hands, to hold them Arm, and to prevent withering if they have been injured. The weeds will cause much more injury to the crop if not eradicated, than they will suffer from cutting off the onjer-roots two ilches under ground, which is not necessary, and should be aroided, but may occasionally happen.

In two weeks or less they will require another hoo ing and weeding similar to the last, and a fortnight after, hoeing again, if not weeding. There should be no hilling or hauling away of dirt, but the surface should be kept level.

Gatherivg.-When the tops die and fall, the crop should be pulled and spread evenly over the ground to dry or cure. The scallions (thick-necked or green onions) with the weeds, if any, should be thrown into heaps or carried off. After three or four days' drying, turn them over carefully with the teeth of a wooden rake, without bruising, and let them dry as many daya more; or instead, as they preserve a brighter color, put them into heaps of two to four bushels, to sweat a ferw days, when, if intended for early market, cut the dead tops off one inch from the bulbs, and barrel to send away; but if wished for storing, they may be left in heaps some weeks, or carried under cover on a floor with the tops on, and piled around the sides of a barn floor, three feet high, or put into bins with slats on the sides, and not close, like open horse-stalls, filling every other one, and putting strips of boards across the ends and through them, or slanting them up so as not to need supports, and leave all the doors open. After a week or ten days' drying as above, put them under cover in any airy place, as a shed, but watch and examine every few days to see if they are gathering moisture, heating and growing; if $\mathrm{BO}$, open and spread to dry again.

STORING FOR WINTER-If the onions are to be kept upon a barn or other floor, pile them one foot and a half or two feet deep, leaving a space of one to two foet all around. Cover them with one thickness of sheets to keep out hay-seed, chaff, etc., and when hard freezing weather sets in, cover one to two feet deep with hay, straw, or any similar substance, filling all the spaces around the heap. Do not disturb them if frozen, until the frost is out, which may be hastened by opening the doors and removing a portion of the covering each day for a week.

A wagon or wood-house tightly boarded, floored, and fitted up with a bin or bins as follows, is undoubtedly the best place, and such as one of our oldest onion-cultivators, after long and sad expericnce, has adopted and used or some jears with perfect success. Set up scantlings for a stall or bin, of three to flre seet wide; on these nail two or three tiers of ten-inch boards two or three inches apart, and as far abore the floor, leaving a wide space, two to four feet at each end, to pass round, and for free circulation of air. Then place every three to four feet, before the onions fill up. on each board, cross-boards eight or ten inrhes wide 
resting or each tier of side.boards, with cleets on each I end, like a wagon-board for a seat-one or two hogse head staves side by side are the cheapest, if the width of the bin is calculated for them, with similar strips resting on these, in number according to the width of the bin, alout one foot apart, running lengthwise-and thus on each tier of side-boards as they are filled, nsing loose side-boards for the top, as high as wished or needed. The ends may be filled up, slanting so as w support themselves, or cross-boards may be fitted in. The spaces under the staves or flat boards will effectually ventilate and prevent heating. The onions should be well dried and have their tops left on, and when first frozen be covered with one or more thicknesses of carpets or old garments, and have them hung around ineir sides. Freezing does them no apparent injury, if they are thawed gradually. When wished for winter's sale, the temperature should not be below freezing, nor much above it, which will have to be regulated by stoves, or by moving them to dry cellars when hard frost comes on.
TO RAISE SEED. - Select a piece of warm, rich ground, manure it well, plough deep, and strike out light furrows two feet and a half apart, and set out, six inches apart, well-bottomed onions, (no scallions,' remembering that "like produces like." Set them in the bottom of the furrows, and cover well. Till the pround as for potatoes, with plough and hoe, ridg ing well. to support the tops. In August, when the seed-pods are half-opened, gather by cutting off the stalks just helow the tops, and spread them on a chamber-floor to dry, and thresh out any time when needed. Or, as mice are very fond of it, spread a few days on sheets in the sin, and when dry, rub the seed out in the hot part of the dav, when it will shell much more easily than in the cooler parts, for it rapidly absorbs a great deal of moisture. Clean it by stirring it in water; the good seed will sink in a few minutes; all the res' should be thrown away with tha chaff. Put the seed into bags, and keep it in a dry olace cent $q^{\circ}$ tho "arot of mice.

\section{BY H. WADE, FLOYD CO., IOWA.}

Frrst select the best and brightest-looking onions for soed, and plant them in rows about two feet apart, one foot in the row, and when they grow up, drive stakes and draw twine along, to keep the heads in their place, until ripe. Then cut them off and tie in bunches of about a dozen heads, and hang them in a shed, where the wind does not blow very much, for a time, and then ruh out and spread thin for a ferr days before putting away for winter, and thus good seed for spring may always be had.

Jow for preparing the ground. I have grown onions on almost all kinds of soil, but the best on a sandy loam. In preparing my garden, out here in the West, I fixed on a place to grow my onions. I dug it two good spades deep and mixed it as well as I could. The soil was pretty sandy and not very rich, but very dry. In the fall I put on good rotten manure of any kind I could get, about four inches thick, and let it lie all winter, and as soon as dry enough in spring, I mixed it sltogether about eight inches deep with a good fourtoothed fork. (When I raised them in fields I used a cultivator for this part of the work.) I then let it lie a few days to dry, and then dragged perfectly, until four inchos of the surface was all quite fine. I have a marker that marks four drills at a time, one foot apart, about one inch deep. A small seed-sower is best for planting. Care must be taken n t to sow too thick, unless you are near a market wher you can sell green onions; then it doen not signify, as thinning loosens the soil for what is left. Rake them in lightly, lengthwise the rows, so as not to get the seed out of the drill; then with a light hand-roller go evenly over the piece each way, and leave it till the onions make their appearance. In cultivating, use a light sharp tooth-rake, head nine inches long, teeth one and a half inches apart, handle six feet long. It is better than a hoe, as you can loosen the soil close to the rows without cutting the roots, and if you made a good seed-bed, a man will do as much again with a rake as a hoe. Rake over every week if the weather permits, as soon as it is dry enough after a hard rain to keep the top from crusting. Attend to this at first well, and you will not regret it.

About June, as soon as the onions are up enough, thin out to about four inches in the row, pulling out at the same time what few weeds are growing with them, and after that, you may run the small rake between the rows occasionally. Onions may always be on one spot in a garden, but you must manure pretty wel every fall, after the ground has been dug. Once in two years dig two spades deep; and if a stiff clay soil, put stones or something at the bottom, for \& underdrain. Good well-rotted barnyard manure is as good as any to manure with. I have grown thein three years in one place, and last year I had the best and handsomest I ever saw. You could hardly tall one from the other.

When the tops begin to fall down, I go orer thex 
and press them all gently down with a rake-head, or comething of that sort, and as soon as the roots let go of the soil, I use a wooden-toothed rake and turn them over, if it is likely to be fine a day or two, and then pick them up and carry them to a shed or barn-floor, and Isy them out thin, till perfuctly dry. After this, a good dry cellar I believe is the best place to keep them
Thes wit mo in Ilinois whon I left, that I could not grow onions in Iowa as I did there, but I find I can and I believe better; but I have not begun to grow them in the deld yet, as we have no market for them. They pay well if you have a market, if you manur well, and care for them as you should.

No. XII.

\section{BY J. B. WAKEMAN, FAIRFIELD CO., CT.}

Ir is over twenty-five years since I raised my first $\mid a$ deep soil, free from stones. But I have raised them crop of onions. I commenced with two rods of ground, successfully on gravelly soil and quite stony. I proand have increased to eight acres. There is but one fer, however, a deep loamy soll. I would plant the place in the United States where more onions are ground with corn or potatoes-I prefer corn-one or raised than here; that is in Danvers, Mass, where it two jears. It should be highly manured, and not a has been stated they raise more than 200,000 bushels single weed allowed to go to seed. When the.corn- year. But New-York market is mostly supplied crop is gathered, prepare the ground in the fall for the from this section. It would be rather a low estimate to place the yield of this town at 140,000 bushels a vear. Great crops were formerly raised in Wethersfleld, but of an inferior quality, rather small, and sent to market in bunches.

I think I can say, from the time that I first com. menced raising onions, up to the present time, I have raised more bushels to the acre than any other person about here. The first and most important item 's the seed. It is very important to know what kind ff onions it was raised from In other crops we can generally tell by the looks of the seed, whether it is good or not. Not 80 with onions. It is impossible to tell by the looks of the seed whether it will raise scallions, or the flat onion, or the round deep onion, which is mostly raised in this section. There was a great deal of seed bought in New-York last jear, by the farmers near here, which raised mostly scallions without bottoms. It has been estimated by many that it was a loss to them of from ten to twelve thousand dollars. It would be some satisfaction to know from what kind of onions it was raised. I think it must be onions that were grown on a poor soil, and were not fit for market, but left until the next year for seed.

I raised the flat onion when I first commenced the business They will not yield one third as much as the round on:on; so we can not judge what the result will be if we do not know what kind of onions our was raised from. We have, by selecting the large round deep onion from year to year, improved our quality and quantity, so that we raise six to nine hundred bushels where we once raised not more than three to five hundred bushels. We select the most colid, largest, deepest, and brightest for seed. Sevaonions should be kept from freezing. A light freezing will sometimes injure the chit or germ.

The best ground for raising them is levol land with next year's crop of onions, by putting on twenty cart. loads of well-rotted manure, fifty bushels to the load, per acre. It should be free from weed-seed, and ploughed in deep, and not liarrowed in the fall. I have ploughed my ground both spring and fall, manuring at the same time. It is not more than half the work to prepare ground for the seed, that was ploughed in the fall, and the yield is as good, if not better Hog. manure is the best, but any kind of strong manure will do. All manure should be free from seed. Manure, either fine or coarse, should be ploughed in deep. If ashes are to be had, put on one to two hundred bushels to the acre. The crop of onions will pay for them the first year, and they will last from five to eight years. Bone dust is a fine manure. The ground in the spring should be prepared for the seed as soon as it is dry, by harrowing with tooth and brush, until the ground is level. It will not do to have the ground too mellow. It should be rather hard to have the onions bottom well. It needs to be very mellow, about an inch deep, and raked off level. It requires from three to four pounds of seed to the acre. I sow them by a machine made very simple, and costing from two to four dollars. It sows two rows at once, twelve inches apart, the wheels being six inches from the hoppers that drop the seed. The first row must be perfectly straight, which will be a guide to the second, and so on. To cover them up, I take a hoe that stands in well, and push it along over the line where the seed is When they get up so that I can see the rows, I commence hoeing them, and as soon as there are any weeds to be seen, weed them; and continue to hoe and weed as long as there is a weed to be seen. It will not pay to sow a piece of onions if they are not taken care of, aud no crop pays better if well tended. There are some farmers that lose one third or more of their crop br not taking proper care of them. and let 
ting ¿- 0 weeds grow after the onions have attained some size. If one intends to raise them year after year on the same piece of ground, (and they will grow as well by heavy manuring as they did the first year,) he must ot let a single weed go to seed.

If the right kind of seed and plenty of manure are used, and the ground cultivated as it ought to be, we may expect from five to eight hundred bushels to the acre. If the ground is free from weeds as it should be, when the crop is gathered in, so much the better for the next year's crop. When most of the onions get ripe, I let them dry one or two days, and when dry rake them in windrows, and when little damp, either at night or morning, pile them up in small heaps, and let them stand till they have no moisture in the top. When it comes a drying day, spread them out, and when perfectly dry, cart them in. They can be kept from two to six feet thick if they are well cured, and put where the air can circulate around them, till very cold weather, and then they must be kept from being frozen too much.

It senmed to me the hardest work that I had ever dxee, to weed the first piece I planted, and it cost more to cultivate my first two rods of ground, than it has as acre since, owing to the ground being full of foul seed.

Onions are the most profitable crop that a farmer can raise, and the quantity has been increased from three hundred to nine hundred bushels per acre, and I think one thousand bushels or mure can be grown by proper cultivation. Red onions are now wholesaling at three dollars per barrel, and white ones at four dol lars per barrel. One year I sold my onions at one dollar a bushel, and sent them to market in the fall be. fore housing. I have sold red onions as high as five dollars a barrel, and white ones at six dollars. There has been no time within twelve years, but that onions would bring two dollars a barrel in the course of the year. There is one thing that farmers have to complain of, and that is, it costs us so much before the onions get into the consumers' hands. It costs us about twenty cents a barrel to send them to New-York, and they are sold to wholesale dealers, who make from twenty-five to fifty cents a barrel, and so it cosis us from sixty cents to one dollar per barrel before theg get into the consumers' hands.

\section{N•. XIII.}

\section{BY LOUIS STRADER, GREEN CO., KY.}

PотАто ONioss are the only variety much cultivated in the Green river country. They are a very pro. lific, mild, and well-flavored vegetable. The sets grow from the roots, numbering from four to fifteen from each ovion, and are much larger than the sets from the red nnions; they are not quite so hardy, however.

Select tho largest ar.: best-shaped sets to raise from. They attain their full sizo the first year after planting. To raise the set;, select large, sound, and well-formed ouions

Fuavinga, Coltivation, Etc.-I much prefer planting in the Ifall; they come much earlier, the yield is larger, and theg are safer in the ground after planting than elsewhere through the winter. Plant about the middle of October for this latitude, earlier further worth, and luter as you go south. Select a situation seutly sloping to the south, a rich, dry, loamy soil, sighbiy manured with well-rotted stable-manure. Plough or spade up the land some nine inches deep, when the ground is in good working condition. Avoid working the land when too weth as it causes it to bake, which is a great drawback to the growth of onions. Pulvertze the soil thoroughly with a hand-rake, by drawing it back and forth until all the clods are broken fine. Out two sticks 18 inches long, and tie one to each end of a line, which should be as long as the piece of ground intended for planting, and with it mark off the ground in rows 18 inches asunder, using the stirks at each end of the line as a measure, sticking them fown to hold the line weil stretched. Scrape out the drills by the side of the rope deep enough to hold the'mions, so that the top may be even with the surface of the ground. Then place the large onions in the drills nine inches from each other, and the sets six inches from centre to centre, and fill up the drill with well-rotted stable-manure. Next, draw up the fine earth so as to make the drill in a ridge, in order to protect the onions from too much freezing. This ridge should be scraped off in the spring, when they begin to grow

If the fall should be favorable, they will soon come up; they should be covered up before hard weather sets in, with corn-stalks, hay, or something of the sort, to protect them during winrer.

They should be uncovered in the spring after the ground cesses to freeze. After this, they should be well worked with a hoe once a week, until they are fully grown, taking care not to disturb the roots too much. About this time the earth should be scraped from them, to uncover the top of the oniong that they may be exposed to the sun, which will ripen them. The earth should not be scraped from them until some of the tops begin to fall over on the ground. Let them remain in this condition until the tops are dead and nearly dry. They should then be pulled up, and 
Hed in bunches, and bung up in an open shed, until thoroughly seasoned; or if the crop is large, they may be spread thin in an open lcin until seasoned, when they may be barrelled up and sent to market.

The above mode of cultirition applies to sets as well as to the grown onions. The sets should be taken up als treated in the same manuer as the large onions If they are not planted in the fall, they should be planted in the spriug as early as the ground will bear working, observing the same directions as in fall planting; omittung the covering of them. In the northern aud middle parts of the United States, sets, sud other ouions designed for planting, should be kept is a warı and dry cellar, boxed up and mixed with dry dirt-that is, when they are nct planted in the fall.

RED ONIOss are not so prolifle, are very strong and highly scented, but are hard5, and keep well through the winter. The sets grow on the top, and have to be well propped up before they ripen, or they will fall down aud rot in wet weather. The same mode of cultivation is to be observed with these, as laid down for the potato onion.

Sealiots are a small variety, which grow in large bunches. The roots resemble garlic, but are much larger. They have nearly gone out of use in this region. Their cultivation is about the same as already laid down for the other varieties.

\section{BY R. I., PLYMOUTH CO., MASS.}

Wry the onion-grov er, soil and position are the first / horse-cultivator, planted eleven br eleven inches apart, and by no means the least important. You can make them grow on almost any soil under favorable circum. stances, but to cultivate successfully, which is the great object, $i t$ is necessary that the soil should partake 'argely of vegetable deposit, be mellow, free from small stones, aud lie as near level as you can have it, so as to prevert copious showers from washing out the seed - which I have known occur on slightly-inclined grades.

When the spot has been selected, put in your plough a foot $w$ sixteen inches deep, in the fall, giving the frost an opportunity 20 operate for you in pulverizing or fining up jour soil, which is very necessary, as I bave found in the course of many years' experience. As soon as the frost is out in the spring, don't lose a single day after the soil is sufficiently dry to workput in the plough not over four or five inches deep, haul on your dressing, and harrow in until it is fully mixed with the soil.

I will here insert a bit of my experience. At the outset of my onion-cultivation, I had a man in my employ whose father owned the farm previous to $\mathrm{my}$ coming into nossession. He was positive I could not raise onicns on that place, as all his ancestors had frailed, after repeated trials ia most farored localities, acd utmost care throughout. Deciding to try for myself, 1 directed him to plough a garden, part of it for onious, only a fow inches deep. On examining the piece, and inquiring of him, I found the whole ploughed as deep as the plough would run, giving as reason that it could be spaded up easier. I had two wus of stones loaded upon a wide-felloed cart, and driven over the piece until it was thoroughly packed down, put on the dressing, and worksd it in with a kept well stirred through the season, and for my labor had forty-seven bushels and three pecks of onions, from seren and a half rods of ground, or at the rate of a thorsand bushels per acre. If you plough or work your soil deep, the roots will consequently strike deep, and hold on so as to afford you a bountiful crop of bsull-necks, or scallions, as my boys call them. I think this the cause of the failure of most persons who are not successful. I have found in cases of mildew that have come under my observation, that those portions of the field were the most affected where the soil was the most mellow.

The quality of dressing used is quite important, and the experience of those who have been in the business is of some value. For the region round Naragansett Bay, R. I., the cultivators of onions prefer a compost of strong hog-pen manure to any other. It should be well pulverized in the field, where it is necessary to have it incorporated with the soil in as tine a state as possible, which will save much after-labor. Do the best you can, you will find enough refuse stuff to rake off. You need not fear doing this part of tho job too well. Some apply good fine sea-weed in the fall, and plough in; others use fish, but these, as a geroral thing, are not obtainable, however valuable. If your soil is rich, a yearly application of fifteen cords of hogpen manure per acre will keep your piece producing indefinitely, as onions, unlike most other crops, im. prove or increase in product by replanting the same spot continuous years. There seems to be something valuable in the tops, leaves, roots, eta, left after a crop is taken off, that is of service to the growth of a suo. ceeding one.

A fow years since, I used frur hundred pounds of 
Peruvian guano on one hundred rods of ground, where corn had been raised the previous season. From this piece I, or rather my boys, one ten, and the other not swelve, tnok four hundred bushels of onions. These were planted $11 \times 5 \frac{1}{\xi}$ inches. Whether like satisfactory results cuuld have been obtained by repeating the experiment, I cau vot say, as I have not had an opportunity of testing the matter since. After your dressing is properly worked in, and ground well raked over, rou are ready for planting, which is done in various ways, according to the fancy or necessity of those who cultivate this crop. If you are purposing to bunch, you want more seed in the hills than if intended for ourreling or selling by the bushel. The same is the case if you wish to obtain large-sized tubers, without so much regard for quantity. For a number of years, (thirteen I believe, ) I planted a piece containing one hundred and sixty-six rods, $11 \times 11$ inches each way, calculating for six or eight seeds in a place, with satisfactory results as to crop Unless the soil is very easily worked, and comprratively clear from weeds, I wonld not, for field-culture, recommend any thicker planting, as the tingers have to do the work of a hoe, which is fatiguing, and also requires much time.

I have planted $11 \times 5 \frac{1}{2}$ inches on clean land, but somehnw did uot find my interest in doing it, as more soed and more time was required in after cultivaticn, and not a satixfactory increase of crop. I have drilled with seed-drills in continuous rows ten inches asunder, plants within an inch or two. Time is saved in planting, but I like the old method of putting down with the fingers, unless you have a very favorable piece for drilling in. I have dropped three fifths of an acre in a day, and have known those accustomed to it to drop an acre. Experiments will soon decide which method is best. If your soil is weedy, I would recommend covering seed with sand, unless the soil is already too sandy. A table spoonful of white sand marks the bill, and you can work the earth sooner than if not sanded, and again, the seed wili germinate quicker, getting start of the weeds. Quite a number of varieties of the onion present themselves from which to make a selection, only a few of which I can speak of from experience. For field culture 'or distant markets, the R. I. red or Weathersfield onion is considered decidedly the best, as it yields as well as any, and keeps decidedly the best, which is one great item of value, as all will testify who have dealt in tho article. The Danvers onion, a yellow variety, is quite popular among growers in the vicinity of Boston, and they claim for it superior flavor as well as good keepIrg qualities; yet I could never have them as sound in spring as the red onion. The white or silver-skin onion is a favorite with marketmen and consumers, Inon their being nlce-looking, and of superior flavorwot so strong as the red. A serious objection to these wheir liability to decar and the necessity, of course. for a ready market and quick consumption The three varieties I have named are all sufficient for you to select from, according as your market may roquire.

As soon as your onions show themselves above the surface, commence hoeing and weeding, as the weeds will surely give you great troukle if you do not Don't allow a weed in the hill if you wish for success The frequency of going over your fields will depend upon the rains and foulness of your soil-you may fix it in your mind that you can not stir the soil too often. Leisure moments can be profitably spent on an onionbed.

The time of gathering the crop is important, and requires good judgment as well as experience. Portions of the hills as well as portions of the field will ripen earlier than others. T the first ripe are suffered to remain until the others that are not ripe are dead, the first will have sent out new roots, which disfigure them much, and the interior of the onion will com. mence growing again, and send up sprouts if time enough is allowed; if not, these are the first to sprout and rot, when gathered in. I keep a good watch of my crop, and as soon as the first indications of a secondgrowth are manifest, I pull all up and lay in rows for curing and topping. They should remain on the ground until the tops are all dead, (except the bullnecks,) before topping, as they are much more liable to sprout and rot, if cut while the tops have sap in them.

It is found economical in pulling to lay three rows or drills together upon the middle row, roots up from the ground as much as possible, with the alternate row reversed thus:

$\begin{array}{llllllll}8 & 8 & 8 & 8 & 8 & 8 & 8 & 8\end{array}$

so that when you commence topping, you take the onion in your left hand, which will bring the top in place for the knife or sheep-shears, (which are often used,) and the onion dropped in the space between the two rows, thus bringing six rows or drills into one. If any weeds are on the ground previous to topping, hoe them up in spaves where your onions are to lay, rake all off clean, for you may have to stir up your onions several times previous to getting in, which can be quickly done with a rake, if no weeds are in the way. Cut the tops about three inches long for bunching, and one inch for barreling. Cutting any shorter than this, increases the chances of decay. Many shippers prefer having tops two inches long, and all the refuse leaves also, if perfectly dry, as on board of vessel and in confined places they sweat freely, and the tops and dry leaves absorb a large quantity of moisture, and thus in a measure prevent heating and decay. If you have not a ready sale for your crop, and find you must store them for a time, don't put them in the cellar, but into some dry room above ground, that will allow you to spread them, not orer two and a half feet deep. and as much less as you can 
During the cold winter of 1856-57, I kept two hundred bushels of onions in a wood-house, that was covered with matched boards. On the inside of stud. ding I tacked up some old boards, and flled the space between them and outside of building with salt hay, not to prevent freezing, but to avoid sudden thawing. I covered the onions with old pieces of carpets, bags, ot. They remained until some time in April, when I took them to market as sound as when put in, not losing more than a bushel. Never allow them to be stirred until you are sure the frost is out, for it will surely ruin them. Neither uncover in the least, until they are entirely free from frost.

I may as well suggest here the propriety of every Jnion-grower raising his own seed-as good seed is all important to success, and you can not be sure of getting it from seed men. In selecting onions for seed, take medium-sized, round, or deep ones, and by persisting in this practice, you will find that your onious will more and more partake of this character, weigh more and keep better than the flat or oval-shaped. Onions are required by law to weigh ffty-six pounds to the bushel, and flat saucer-shaped ones will not some up to the standard.

If you wish to have early onions for marketing, sow in September, cover the bed, when the frost first hardens the ground, with sea-weed, or any other non-conductor, to prevent thawing in winter, uncover in spring, as soon as you find the frost out, and you have onions with two months the start of those put in, in the spring.

There is a variety called Potato Onion, that is early and much used by market-gardeners. They grow from planting the tuber, attaching themselves around
I the one planted. I have had marvelous increase from this variety.

As it may not be uninteresting to a beginner, I will state the result of my experience in cultivating onions for successive years. In 1836, I took up a place for onions containing an acre and six rods Soil good, some weeds, and some small stones to be worked out. I planted this piece over a dozen years, drilling $11 \times 11$ inches all the time. My smallest crop was $\mathbf{3 5 7}$ bushels, and my largest 723 bushels, and no season under $5 \cap 0$ bushels, except the one I have named as the least, which was a very wet season, and the crop scalded or mildewed. The season I obtained the 723 bushels, a friend of mine bad over 1700 bushels from two acres, which he planted in drills $11 \times 5 \frac{1}{2}$ inche These crops were uuusually large. I also kept an ac count of expenses on crop up to timo of eale. In thie account I charged the crops with every item of ex. pense, interest on land, dressing, labor, tools, etc, etc, and found that I could raise onions for about 17 cents per bushel. Some seasous they cost me more, others less, according to yield of crop, or extra amount of lab to keep clean in wet seasons. They never cost me over twenty, nor under thirteen cents per bushel. As to price obtained, I am not so well able to state, as I often sold in different places, and at different times, and account of sales going in with other arti. cles. I never sold a crop, however, under thirty-one cents, and have often sold for a dollar per bushel. The papers report at this time onions in New.York at two dollars and a half per barrel.-From the above statement, the conclusion is reached, that $I$ have found the cultivation of onions profitable, and that any one may do the same under favorable circumstances.

No. $\mathbf{X V}$.

\section{BY SAMUEL BOUTON, FAIRFIELD CO., CT.}

VARIETIES-Onions wibl grow on almost any soil that is not too dry. The kind of onions which can be raised with the most advantage will depend on the time wher it is designed to market the crop. If intended for winter, the variety known as the black onion, will be found the best, as they are very solid and firm, and their keeping qualities can cot be surpassed. If for a fall market, that variety known as the Wethersfleld Red is better, as the yield will be somewhat greater, and they will be ripe a fow days earlier. if for an early market, potato onions should be rai. ad. The advantages of the potato onion over the other rind, are, first, an early market and the use of the Frownd for some other crop, after they are off; and econd, a high price, and one third less labor in their sultivation. The disadvantages are, first, a great out. lay is required for seed; and second, it is difficult to keep the seed during the winter. I would not recom. mend them for field cultivation, unless un a small scale. As the mode of cultivation for these different kinds is essentially the same, one description will answer for the whole.

SEED.-The seed should be procured of some reliable seed-grower, if possible out of the immediate neighborhood, as seed brought from a distance will do better than that which is grown on tne ground, where the crop is to be raised. If this can not be done, the seed may be raised on he spot. Sound, firm roots should be selected for seed. They should be put in the ground as soon as the frost is out. They should be set in rows, twelve inches apart one way, by about six tha other. Light poles or twine mas be rur 
through the rows to support the stalks, otherwise they will be liable to be blown down by high winds, which will injure the seed. The seed should be gathered when fully ripe. It may be separated from the husk by rubbing between a good pair of leather mittens, or, if the quantity is large, it may be threshed by the flail. The dust may now be separated by the fan. The seed should then be put into water sufficient to cover it, when the blasted, if any, will swim. These should be uhrown away; the remainder may be carefully dried and put up for use.

Care should be taken in selecting seed, to procure a good article, as this is the rock on which the hopes of the cultivator are frequently shipwrecked. If the seed be shrunk, scallions may be the only product. Old seed is not so likely to grow as new, but if it must be planted, it should be soaked a few hours in water. They should be planted as soon as the ground is sufficiently dry. The middle or latter part of April is in this latitude about the time. A lato crop is more dependent on the weather than an early one. If the planting is delayed till the middle of Mas, a cron of scallions may be the only product.

MANURE.-The best manure for onions, is night-soil. Twenty loads, of twenty-five bushels each, will is for an acre of ground. If this can not be had, sometbing from the hog-pen, at the rate of thirty loads to the acre, will be found an excellent manure. If the ground is heavy and clayey, a compost may be made $\alpha$ enfermented horse-manure and muck. It mav be put together is about equal quantities, and should be placed in alternate layers, first a layer of manure, three or four inches thick, spread on the ground, then a coat of muck, about the same thickness, and proceed in this way, till the whole is finished. The heat arising from the manure will rapidly decompose the muck, while the muck will retain the ammonia arising from the manure, and thus both will be improved. In about six weeks it will be fit for use. Thirty loads to the acre will be a good dressing.

If the ground is sandy and gravelly, a compost should be made of muck and unleached wood-ashes, at the rate of about half a bushel of ashes for twentyfive bushels of muck; it should be placed in alternate layers. In two or three months it will be fix for use. If it should be shoveled over once or twice, it will be improved: forty loads will be sufficient for an acre. If none of these can be had, fine well-rotted barnyard man're should be applied at the rate of not less than thirty loads to the acre. The manure should be spread evenly over the ground, and ploughed immediately in, six or eight irches deep. The subsoil plough should be run in every furrow, sixteen or eighteen inches deep The ground should now be ploughed with a surface-plough, ten or twelve inches deep. If two hundred pounds of the best Peruvian guano be now nowed on and harrowed in, it will give the plants a fine start. The ground should be raked with a gardeo. rake, and made as level as possible.

Planting and Cultivation.-The send may now be planted; four pounds of seed will be sufficient for an acre. The rows should bis twelve inches apart. The drill should be so constructed as to plant the seed in hills, four inches apart in the rows, and three or four seeds in a place. This will be found more convenient for hoeing than a continuous drill, and the yield will be as good. The seed should be covered about half an inch deep, either oy the drill, or by passing the hoe lightly over the rows.

As soon as the plants can be seen, they should be hoed. This may be done if the ground is free from weeds, by drawing a small hand-cultivator between them; or, if the ground is weedy, the hoe must be used. The ground sinould next be stirred around the roots of the plants. A small hoe, with four prongs on one side, and a narrow edge on the other, will be found very conrenient. These are made of malleable iron, and are sold at six cents each. If the ground is freo from weeds, four hoeings may be sufficient. If the crop appear sluggish in the early stages of its growth, a liquid manure may be prepared by dissolving one hundred pounds of Peruvian Guano in water, and şrinkling it on with a watering-pot. This will be sufficient for an acre of ground.

At the second hoeing, carrots may be drilled between the rows, if desired. Drilled in at this time, they will ba nc injury to the onion crop, and I have frequently known the carrots to pay all the expense of cultivating both crops. If this is not done, it is well to sow the ground with armmon turnips before the last hoeing, as a good crop may be raised in this way with no other trouble than sowing the seed and harvesting the crop.

HARVESTING SNI STORING.-The onions, whep ripe, may be turned out of the ground by passing a hoe under the rows. If intended for winter, they should be left on the ground till perfectly dry. If the weather is dry, three or four days will answer. The husks will then peel off, and they will assume a bright-red color, which makes them more salable. They should be gathered and stored without trimming. If any still remain with green tops, they ought to be thrown out, as they may licat.

A cool dry cellar will be lound the best place for keeping onions - the cellar of some out-building, as a varn or carriage-house. The cellar of a dwelling. houss is generally too warm. A little freezing will do them no harm. A bin should be made in some dry corner, with a floor raised a few inches from the ground. Care should be taken to keep them perfectly dry, or they will be virv likely to rot. Care should likewase be taken in carting and olacing in the cellar, that the onions are not bruised, or tlisv will sonn deeay Ground treated as above described, may be planted witl onion every year in succession, and is this treatment is perwo vered in, the crop will improve for seviras vens 
No. XVI.

\section{BY THOMAS FULTON, WAYNE CO., PA.}

Quauries or LAND.-To raise a good crop of onions, the land is required to be, 1st. New, that is, lately bro ught in from rich sod, and then there will be but few weeds to contend with in the culture; 2 d. Rich on the top: the land can not be made too rich for onions, but the richness should be on the top of the laud, as the onion roots will not descend into the ground more than an inch or an inch and a half at furthest; and 3d. The land should be well settled, as, if the land be rich and soft, the onions will grow to tops, or what are called (in Europe) "scallions," but if the land has been well settled, they will grow to roots, or what is called onions.

Preparation of Ground. - To obtain the above results, the land should be prepared the previous year. In Exrope, especially in the north of Ireland, where onions are extensively raised as a paying crop for market, the land (generally rich sod) is ploughed early in spring, neatly and light, into narrow ridges, say five feet ridge and furrow, and about the middle of May, the land is harrowed, and the manure (good barnyard) put on; the ridges are lined out four feet wide, and the manure spread evenly and broken fine. It is then planted with potatoes. The seed is dropped in rows across the ridge, about eignt inches apart in the row, and the rows about a foot from each other. The potatoes are then covered about an inch deep out of the furrow, the mould spread evenly and broken fine. They remain so until the potato plants begin to appear, or when the "buds" are bursting the top of the land. Then the furrows are dug with a spade, and the mould broken fine in them; the mould is shoveled out of the furrow, and spread evenly over the ridge about two iuches deep, after which they require no more labor (except woeding, which should not be neglected, lest the seeds of the weeds remain and give trouble in the ensuing crop) until the fall, when the potatoes are fit for digging up. This is done with a spade : the ridge .s all dug orer evenly, the potatoes picked up, care being taken to keep the rich mould on the top of the ridge. The land remains = this way until sowing-time the ensuing spring. The land is well raked with an iron garden-rake. This will make sufficient mould. The onion seed is then so $\mathrm{kn}$, and covered by raking it in; it is then clapped over with the back of a spade, or by passing a hand-roller over it; this is called sowing on the "uinter face," and I liave never seen this fail to produce a good crop of onions. I have seen acres prepared and raised in this way.

The objection to the above mode of preparing the land ir. th is conntry is, that it requires a goor? deal of manual labor, which is scarce and expensive here Where this is the crse-

SECOND METHOD - I would say, plough rich sou, sow it in buckwheat, and when the buckwheat is cut and taken off, plough the land neatly and light into narrow ridges, five feet ridge and furrow; let it remain for some time to settle and rot any weeds, then harrow well and put on the manure. Mark or line out the ridges four feet wide, leaving one foot for a furrow; spread the manure evenly, and break it fine. Trench up the furrows and cover the manure evenly, let the land remain until sowing time in spring, and prepare and put in the onion seed on the "winter face," as above. I have not tried this, hut I believe it will be found to produce a good crop.

THIRD METHOD.-To prepare the land the fall pro vious to sowing the onion seed, for small quantities.

Dig the patch (intended for onions) with a spade, a foot deep, turn the top down, cover all grass or woeds, and break it fine. Then mark out the ridges four fert wide, leaving a foot for a furrow between the ridges Then take a hoe, and draw the mould evenly about an inch and a half deep from balf-way across the ridges on either side, to the place marked out for the firrow: spread the manure on the ridge (thus hollowed) evenly, and break it fine; shovel the mould collected on the furrow, and cover the manure, leave it so until sowing. time the ensuing spring; then rake it well, and sow the onion seed, cover with the rake, and clap it over with the back of a spade.

Fodrth MeтhoD.-To prepare the land at the time of sowing the onion seed : dig it a foot deep, unark out the ridges as in third method, and spread on the manure, which should be well-rotted cow-dung. Horse-dung is not good-it has a teudency to get dry and moulds. Break the manure very fine, and cover it out of the furrow an inch and a half deep; pass the rake over it, and ow the seed; cover with the rake, and clap it well all over with a spade, to settle and close the land. I have raised good crops of ouions in both these ways, and the largest onions I ever raised, or saw raised, were in this last way; but the manure was takı $\mathrm{n}$ out of the privy, and mixed with an equal quantity of house-ashes.

In selecting the seed, go to a respectable seed-atore. select that which has the least small or blind seeds in it. If it is new seed, it is softer, and tastee stronger of the onion than if it is old seed. White shote or white flat, mixed with a little red, say one $\mathrm{tl}$.rd red, will do well.

TIME OF SOwiNe tuB SEED._-:: this sountry we 
can not fx a certain time. In some places and some seasons the land may be ready to receive the seed earlier than at others; but when the frost is fully out, and the land dry enough for sowing, and vegetation has set in, then I would sow the seed; about a seed to the square inch is sufficient.

WeEDive THE ONions-When they come up, if weeds appear, pick them out as soon as possible. You con with more safety to the crop pull out the weeds when sm ill, than if they are allowed to grow large: then they are liable to injure the roots of the onions in pullıng them, and if allowed to grow large, they exhaust the land, the whole strength of which should go to raise the onions.

Management of THz Crop.-When the onions bave got up to be pretty large in the tops, (in Europe,) those of them which do not show a disposition to make a head, but grow up with a luxuriant top, (these they call "scallions,") are pulled out, and taken to market; this gives room and air to those that are forming the opion at the reot. When they begin to ripen, which they will show by the tops beginning to wither, then with the hand twist the stems of those which still -how a disposition to grow to tops and not make root, about half-way up between the root and where the tops branch off; this will prevent the sap from going to the top, and cause them to grow at the root. When they get ripe and fit for pulling, which will be shown by the tops withering off, pull those that are thus withered off, and dry them on cloths until they are thoroughly dried. Those whose tops are sut fully withered, leave remaining some time longer, an : twist the tops a little more severely; and when you think they will make no further improvement by remaining, pull them all up, and string them like apples, passing the needle through the stems an inch or two above the head, and hang them up $h$ iry either in the sunshine by day, bringing them in by night, or near to the fire or stove, until they are fully dried.

Then take the strings, and those whose tops are not fully withered off, and with a penknife open the dry peels a little off above the head, and with the blade of the penknife scoop the stems out of the heart of the onion, and clos: up the withered peels on the top. This is called "gelding the onion" This prevents them from spouting when they are kept over, as such onions have a tendency to sprout if not used soon.

Then the onions are ready for marketing. This is done according to the wishes of the cultivator. Some pick them, and sell the best at the highest price, and the others at what they will bring, and some take them all together, and sell at an average price for the whole.

NoTES.-Six pounds of good seed will bo sufficient for an acre.

There are in an acre five hundred and twenty perchen of a five foot wide ridge and furrow, which will, if well managed, produce over a bushel to the perch or rod.

"Twenty wagon loads of good manure will manure an acre well.

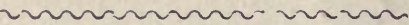

No. XVII.

\section{BY STILLMAN MORGAN, ADDISON CO, VT.}

If a man has only a small piece of ground that he can call his own, perhaps there is no crop more profitable than the onion crop. The writer has raised this vegetable each year for thirty years. His success is owing to experiments tried and varied until the best is found.

THE GARDENRR - You wish only to cultivate from one bushel to five. Find the "potato onion." But if you can not find that kind, get the "top onion," which is nearest to it. The reason I recommend these varieties to the gardener is, that the crop is sure, and always grows clear of maggots. If you bave plenty ot them, take great and small, and use them all for seed.

For THE FreLD.- Use the common black seed of the white globe, or the "Wethersfield red;" I prefer the latter. The Wethersfield reds look best in the nalf-bushel, yield best, and sell best in market. If you take any other kind, look out for good yielders.

['REPARATION OF FROUND.- - Select interval, made land. that seems to have been brought from all direc. tions; no matter if there is a good proportion of musk. But if it is clear muck, cart on gravel, a good mixture. If your ground be clay, cart on loam or any kind of light soil. But if your ground is light loam on sandy soil, cart on clay quite abundantly. But if your land is a naked rock, and nobody will let you into their field for materials to make land of, then go into the highway ; find a "sag" or low place, that has received wash from roads or buildings or any where else. Cart it to the place desired. And then you have an onionbed for a hundred years-don't change places often. When the soil is to your mind, then cart on any kind of rich manure; do this early, and have the ground ploughed early in September. Then there will be time for all foul seeds to grow, but not Laving time to mature, you will loose your weeds.

Then in the spring, as early as possible, plough again that will leave the manure well mixed and near the top. Now put on your harrow or muck-rake, and vulverize as fine as possible. Strike out your urcusd 
to hacdsome form. Then if you have enough ground w pay, get a professional seed-sower. He will come with a little machine, and sow three or four rows at a time as fast as he can walk. Gauge your machine so as to have the onions, when grown, so near as to touch each other. But have the rows so far apart, that a common hoo will pass between. Du not be afraid of tramping your ground, especially if the soil is light.

WEEDIra. - As the roots of onions, many of them, grow near the surface, do not chop down deep with your hoe to cut them off; many a good bed of onions has been spoiled by late weeding, by disturbing the ground too deeply. I like to have my onions hoed in the morning, while the dew is on. If you are going to raise onions indeed, don't be afraid of soiling your knees. Do not cover up the onion too deep, nor leave it so as to fall this way and that, by taking away too much dirt from it.

"TOP ONIONs" OB "Potato."-When your ground is ready, have a sort of furrowing instrument. It is a home-made thing. Make a thing just like a rake, with oo teeth in it; then put in as many teeth as you wish to mark rows with, once going across the bed. Or instead of teeth, nail on rockers. Then push the rake so made, before you. And when you return, place the end-rocker in the outside furrow; thus do until your rows are all marked.

SowIva.-Take your onions or seed in a basket by your side, go down on your knees, and put in one at a time. But be sure you put it right end up, or the onion will grow heels over head. Cover the seed just ont of sight.

SALT. - When you have done planting or sowing your onions, whatever kind they are, sow on salt, common salt. Sow as thick as peas. I would do this again, perhaps in June, not so much the last time. Whether field or garden onions, go out in the morning while the dew is on, or after a shower, take dry unleached ashes, and with a shingle throw them up into the air, and let them fall in a cloud of dust on the onions. Repeat this two or three times while the onions are growing. And I had forgotton to say that coal-dust, taken from ald coal-pits or from forges, with leached ashes coated an and well mixed in the wo en l bofore ploughing, will well pay. If your land is quite clayey, lesve out the asher. I think the coal-dust and salt, beside very much quickening the growth of these regetables, kees off the maggot-fly.

Go into store-cellars, where they have sold fish and meat, and they will give you the salt and brine. And when you are about it, get all they can spare. Then if you have any to spare, put it on your murk heap, fos other crops.

If you are at a loss what kind of onions to cultivate, inquire for the greatest yielders and the quickest to sell.

Then the onlons you wish to keep for your own use, trace them up and hang them in a dry place until well seasoned, then hang them in the cellar-way for all winter.

If you have any to sell, take a fair ppecimen of them; then go and show them where you wish to sell. But by all means do not let them remain long on your hands. If you keep them long in heaps, they will rot And then you had better have any thing else. Let them slide at the then present prices. You can well afford them for fify cents a bushel, but you will oftener get a dollar. For your seed potato-onions, you should have from two dollars to two and a half per bushel. The soed of the top-onions I have usually sold for from four to five dollars per bushel. I have sent out barrels of this seed to distant States thougb I have none now to sell.

Of the top-onions, I have :aised at the rate of seren hundred bushels per acre. And one of my neighbors, who followed my directions, raised at the rate of eight hundred per acre. But I have never seen any kind that yields so well as the Wethersfield reds.

If you wish to get good onions in June, sot ont any kind of an old onion, and when the top begins to form as if to go to seed, cut off the main stalk, and it will bottom. But these bottoms will never winter, but rot. Eat them green, or supply the market.

If you want good, new, fresh onions in May, go to the woods, and search in low places, and there gather leeks. Or if you prefer it, raise cives, whicin are the lowest species of the onion. 


\section{ONION GROWING IN THE SOUTHERN STATES.}

It is a common impression that onions can not be successfully raised from seeds, or "black seeds," as growers term it, much south of latitude $40^{\circ}$. In localities south of this, it is asserted that a crop can only be grown with certainty by the use of sets. That a Southern climate is not unfavorable to the onion, is shown by the fine specimens sent from Spain and Portugal to the English markets, and of late years to our own large cities. The onions grown in Bermuda are so fine as to be regarded in our cities as a distinct variety, while New Mexico and Mexico excel all the localities mentioned in the great size, combined with tenderness and mild flavor of their onions. The assertion that onions can not be grown from seeds in the Southern States, is met by the fact that large quantities are annually sent from Georgia and other States to the Northern markets. Though a share of these are grown from sets, the larger portion are from the seed. Dr. A. Oemler, near Savannah, Ga., reports having raised the "Giant Rocca" onion at the rate of ten hundred and fifty bushels to the acre, a yield from the seed that would be remarkably large in any locality.

Probably the failures with onions from seed have been due more to late sowing than to any other cause. Early sowing is very necessary at the North, and is still more so at the South. The roots of the onion do not descend into the soil very far, and the crop is one of those most disastrously affected by drouth. In the vicinity of Norfolk, Va., and in Maryland, the "Potato Onion" is grown almost exclusively, and this variety can only be grown by planting the sets, or small bulbs. In Georgia, the "Red Wethersfield" añd the "Yellow Danvers" are preferred. Some of the recent varieties from the south of Eurcpe are productive, but are either too small or too large to suit our markets. Those who raise onions for the Northern markets, find that their product brings the best prices when it comes in just as the supply from Bermuda ceases, and before that of Northern growth is ready. Hence the time of sowing is regulated with a vlew to this, and it is not desirable in this case, as with other vegetables, to place the crop on the market at the earliest possible date. The conditions of success with the Southern onion crop are the same as at the North. The soil must be light and loams, as free as possible from weeds, and be highly manured. As at the North, the same land is continued in onions for an indefinite number of years, making a change occasionally in the kind of manure applied. The cow pea, with its abundance of succulent foliage, allows the Southern grower to supply the soil with a large amount of regetahle matter. As soon as the onions are off, the soil is sown to cow peas. The pea vines, usually killed by frost, are allowed to lie until the first part of December, when they are turned under, burying them deeply. Not ouly do the pea vines enrich the soil, but they form such a dense mat that weeds can get no foothoid. The time for sowing onion seed near Savannan is about the first of January, which gives the pea vines an opportunity to decay before the seeds are put in. By sowing at this time, the young onions escape the heavy rains, and the severe cold which sometimes occurs, to which those sown two months or more earlier are exposed, while the time of growth, owing to more favorable weather, is made much shorter.

The cultivation of the growing crop presents no features peculiar to the Southern States. There, as elsewhere, success depends upon thorough and prompt weeding. The smaller the weeds, when hand weeding in the rows is done, the less the chance of injury to the onions by disturbing their roots in pulling up a large weed, the root of which has taken possession of the soil.

The onions indicate that they have ceased to grow and are mature, by the falling over of the tops. Usually the whole crop is not marketed at once, but successive shipments are made. For this reason, the field is gone over sereral times, at each time pulling those bulbs, the tops of which have fallen. They may be packed at once, or be left on the ground for a few days, in order to diy off The tops are cut off with a sharp knife, leaving an inch or so of neck, and packed in crates holding a bushel each.

\section{ONION SETS.}

An onion set is an onion raised from seed and which has ripened while very small. This result is produced by sowing the seed thickly. The young bulbs start as usual, but as a dozen or more are struggling for the nutriment usually given to a single bulb, they fail to increase in size, and come to maturity while yet very small. When these sets are planted out, thes are under inore favorable conditions, and at once increase in size, and complete the growth which was arrested in the first season.

Onion sets should be as small as possible, as a greater number ure contained in a given measure; not only this, but the smaller they are, the less risk is there that they will run up to seed. They vary from half an inch in diameter down to the size of a pea. There are several methods of growing sets, but all have the same end in view, the crowded condition of the bulbs. One plan is to stretch a line, and drill in six rows of seed at an inch and a half or two inches apart. The drill is set to drop five or six seeds to each inch of row. This will give thirty to thirty-six seeds to each lineal inch of the bed of six rows. At a sufficient distance from this to allow of the use of the cultivator, usually thirty inches, another bed of six 
rows is sown, and 80 on. The land will thus be laid off in narrow beds of six crowded rows, each separated from the next by an alley, which ean be kept clean by the use of the cultivator. The beds themselres must be kept free from weeds by the use of a narrow weeding hoe, supplemented by hand-weeding.

Another plan is to mark the land in drills, nine inches apart, by the use of a marker. Each seventh row is not sown, which leaves an elgliteeu-inch path between every two beds of six rows each. The seed is sown very thickly in the drills, using about thirty pounds to the acre. Unless the crop is kept clean while growing, it will be a total loss. As with large onions, the sets show that they are ripe by the withering of the tops. They are usually dug by running a trowel under them and throwing them upon a siere, of the proper size to free them from the soil and retain the bulbs.
It is very difficult to keep sets in good condition during the winter. Before they are housed at all, they should be exposed to the sun and air for a few days, covering them at night. They must then be stored in an airy loft, in layers not over three or four fnches thick. When freezing weather is at hand, the sets are brought together in heaps, and covered with straw or with mats. Owing to the difficulty in keeping the sets, it is better to plant them in the fall.

Land for raising onions from sets is enriched and prepared in the same manner as for sowing the seed. The rows are marked at the desired distances apart, usually ten inches, and the sets are planted two or three inches apart in the row. The sets are pressed into the fine, mellow soil by the use of the thumb and finger, always taking care to place them with the root end down. The work is finished by going over the rows with a wooden rake.

\section{RAISING ONION SEED.}

While onion seed, if properly kept, will often germinate nearly as well when two years old, it is not safe to depend upon seed that is over a year old. In either case, the seed should be tested, - as all of that which is only a year old will not germinate, and sometimes a very large share will be abortive. Fifty or a hundred seeds should be counted out, and either planted in a pot or box of soil, or placed in a folded cloth or paper, between two plates, where they can be kept moist and warm. The pcrcentage of good seed in a given lot being ascertained, the drill should be set to sow a sufficient number of sceds to make sure of a good stand.

The freshness and vitality of the seed are of great importance, but it is equally important that the seed should come from a good stock. Seed raised from onions planted out promiscuously, or even from the "culls" left after selecting all the best bulbs for mar ket, may look well and germinate freely, hut the crop will be far from satisfactory, and will be likely to have an undue share of "scallions." For this no test can be applied, and we can only rely upon the reputation of the grower cf the secds.

While there are some growers of onion seed who have a reputation for the quality of their product, and endearor to maintain it, there is much seed in the market which one runs a great risk in buying. Unless the onion-grower can be sure of getting seeds true to their kind, and of a strain likely to produce few scaliions, he had far better raise his own seed.

Very few are aware how readily the onion may be modified by a few years of careful selection. It is well known that the more nearly globular an onion is in shape, other things being equal, the greater the number of bushels that can be grown to the acre. If we bave a variety that is desirable in every other respect, except that the bulbs are too flat, we can in a few years develop it into a globular onlon. Each,successive year, the bulbs which show the slightest departure from the general flat form are selected for seed. This, at first, may be almost imperceptible; but there will be variations, however insignificant, and these must be encouraged. By selecting each year the least flat bulbs, we soon may be able to select those the most round, and nltimately have those tbat are quite globular.

An onion, to keep well, should have a very short neck, and at maturity the bulb should be firm and solid around and at the base of the neck. A wellknown Connecticut seed-grower of the writer's acquaintance worked for several years to reduce and improve the neck, and the results were most striking.

In the first place, the grower of onion seed should have in view his ideal onion; $i . e_{\text {., }}$ fix in his mind the kind of onion he would hare, and, in selecting his bulbs for seed, choose only those which show the nearest approach to that ideal.

Onions set out for seed do not need a rich soil, as too much manure is said to diminish the fertility of the flowers, and cause many to blight.

The bulbs selected for seed may be kept until spring, but it is much betier to plant them out in the fall. They should be put out some wecks before really cold weather sets in, in order that they may form roots and get well established before the ground freezes. Early in October is a good time in the Northern States. By planting at this time the job is out of the way; there is no difficulty about keeping the seed onions through the winter, and there is no danger that some one may take 2 fancy to carry such onions to the kitchen.

The onions for seed may be set out in rows far enough apart to work with a horse-cultivator, or, if to be kept clean by hand, the rows may be twelve to eighteen inches apart. Opcn a furrow about six inches deep, set in the onions six or eight inches apart in the furrow, and cover with the hoe. In spring, use the cultivator or hoe as soon as the soil is dry ecough, and keep down the weeds antil the crop is ripe. The clustar of seeds is quite heary, and as the stalks are 
from three to five feet high, according to the variety, they are apt to be prostrated by a wind, and many of the seeds wasted. To prevent this, drive stakes at each end of the row, and every eight or ten feet of its length. Pass some cheap twine along each side of the row, making it fast to the stakes. The twine should be within a few inches of the seed clusters.

The seed is known to be mature when the capsules or pods lose their green color and turn yellowish; when some of the pods break open, the heads in which this occurs may be cut. If the crop ripens unevenly, it may be necessary to go over it two or three times, and cut those that are ready. As some of the seed will shell out and be lost, it is well to receive the clusters in a bucket, or in a basket in which a cloth is laid. In cutting, leave six or eight inches of the stalk at- tached to the head; the partly-matured seeds will ripen up much better than if the stem were cut close. Spread the seed clusters upon a tight floor of an airy loft. If the floor is not tight, spread a barn sheet or other cloth, to allow the scattered seeds to be saved.

When the pods are quite dry, they are to be thrashed, and the seeds winnowed by running them through a fanning-mill at least twice. After the mill will remove nothing more, the seeds are placed, a few pounds at a time, in a bucket or tub of water, stirring for a short time; allow the good seed to settle, and gently pour off the water with the chaff and imperfect seeds which float upon the surface. The seeds are then to be spread thinly on boards or on sieves, to dry, and only stored away when quite free from dampness.

\section{"RARE-RIPES"-TOP OR TREE ONIONS-POTATO ONIONS.}

Many are fond of green or unripe onions, which are eaten raw, usually sliced in vinegar. The marketgardeners near cities commonly sell a large share, if not all of their crop in the partly grown, immature state. When bunched in this condition, the onions bring a larger price than if they were allowed to ripen. Green onions of this kind are usually very strong and often hard. Much milder and more succulent green onions are produced as follows: When an onion is set out for seed, several leaves are produced, and finally a flower stalk pushes up among them. As this leaf-growth, which takes place at the expense of the old bulb, goes on, a new bulb is at the same time formed by the lower parts of the leaves, and in the centre of the old bulb, and it is this new one which bears the flowers and seeds. Sometimes there are two or three of these small bulbs formed within an onion. If these young bulbs are pulled when the flower stalk first shows itself, or even before, they will be found vastly preferable to any other form of green onion. In New England, where they are often found in the markets, these are known as "Rare-ripes" or "Rare-ripe Onions;" but in New York the Shallot, a different species, is the flrst green onlon in the market. Any onions that have sprouted, or those too small to be salable are set out in very early spring to produce rare-ripes.

\section{The Top or Tree Onion.}

A number of plants are known in which there are varieties that bear a cluster of green leaves in the place of flowers. In one of the wild garlics, a common weed of our fields, flowers are rarely produced, but in their place is a cluster of minute bulbs. In the top-onion the same thing takes place, and instead of flowers, the stem bears a dense cluster of little onions, from the size of a boy's marble, downwards. When these small bulbs are set out in the spring, they increase in size and form a large haudsome onion. This onion, when planted out the next year, will produce a crop of small bulbs and so on. It possesses no advantage over ordinary onions, and is cultivated mainly as a curiosity.

\section{The Potato Onion.}

This is a variety of the onion which has completely lost the habit of producing flowers and seeds; it does not even push up a flower stem.

Under the erroneous impression that it was introduced into England from Egypt it is sometimes called the "Egyptian Onion ;" in this country it is often known as the "English Multiplier," and "Underground Onion" is still another name for it. It is a medium-sized, yellowish-brown onion, with a rather stronger flavor than the common kinds. If a large Potato Onion be planted in spring, it will produce a cluster, sometimes as many as a dozen, of smaller bulbs, varying in size, from a filbert, upwards. These small onions, wheu planted next year, will each increase in size to form a large bulb. The generations thus alternate. One-year offsets, or small bulbs, are produced, and the next year these grow to the full size. Ordinarily it would take two years to grow an onion of this kind, but in practice, some of the bulbs in a cluster of small ones, are often large enough for use, and when a small bulb is set out, it, besides growing to a large bulb, often produces several small ones also. So often does this occur, that, in cultivation on a small scale, it is not necessary to grow a lot of offsets especially for "seed," as enough are usually produced, attached to the large bulbs. This onion is very hardy and may remain in the ground all winter, It is also early. In some localities, especially near Norfolk, Va., this variety is used as the market crop, to the exclusion of those from seeds. 


\title{
RAISING ONIONS.
}

\author{
BY A CONNECTICUT SEED-GROWER.
}

The reason why many do not succeed in their first attempt at raising onions is because they do not select ground which has been suitably prepared in the cultivation of the two or three previous crops. It is a mistake that onions do better, year after year, on the same ground, simply because onions follow onions. It is the higher manuring, more thorough pulverization and mixture of the soil and manures, and the cleaner and more careful cultivation required every year for onions, than is given to any other crop, that fit ground better for them.

Onions will undoubtedly succeed better many years on the same ground than most other regetables, but there is a limit to this success. In Wethersfield, Conn., formerly so famous for its onlons, the cultivation has greatly declined on account of the diminished product to the acre. The onions grown there now in many of the old gardens are smail ; they start quickly and grow vigorously the forepart of the season, but suddenly meet with a check when they should go on growing, even if there be no signs of smut or blast, and ripen too early to attain their former size and productiveness. Much larger crops are now grown in other towns.

One great trouble among begicners on uew ground is that the onions will not bottom and ripen at the usual time, but continue to grow all the season and produce tuo many "stiff necks" or scalliuns. There are several causes for this. One is, the land, which is toc poor to commence cultivation upon, is beavily manured and plowed deep, bringing the poor subsoll to the surface. The seed in such soil comes up weak, if at all, and the onions grow very slowly until they get bold of the decomposed manure, when it is too late in the season for them to mature. Late sowing, a wet season, and foreigu or bad seed, are other causes of scallions. If onions do not begin to bottom before September rains, they never will.

The onion is not so particular about the character of the original soil as many suppose. Good crops are obtained on almost any soil, not too wet or too dry, except a stiff clay, light sand, or hungry gravel. It is essential, bowerer, that the land should have been made rich by the thorough incorporation of manures and in clean tillage for at least two years from the sod. Corn, and then potatoes, carrots, or beets, are good preparatory crops. One or two bearily manured tobacco crops admirably fit the ground for onions : old vetable gardens are perhaps the best, except where cabbages have been grown, which are the worst of all crops to precede onions. Heavy or rather clayey, moist, not wet, loam, generally produces the largest onions. If coarse manure is to-be used, spread on twenty to thirty loads to the acre late in the fall, say, about the middle of November, and plow it in not very deep; or use one ton of fish guano, spread on after plowing and harrow it in. If raw flish is put on in the spring, the onlons will continue to grow until too late to ripen. In the spring, as soon as the ground will work, plow four inches deep, and spread on a good dressing of fine compost, or three bundred pounds of Peruvian guano or superphosphate of lime, and harrow it in well; back harrow and harrow again, and if not smooth enough, dress with rakes. When not manured in the fall, fine hog-pen or stable manure, free from grass and weed seeds, should be plowed in in the spring and the guano or other fertilizers harrowed in.

Every farmer and gardener should have a reel and line, and a marking rake. They will save a great many steps in laying out; besides, the straight and nniform rows enable the workmen to accomplish a great deal more in cultirating and weeding with the modern hand-weeding implements.

The Reel below may be made of wood, though iron (which may be bought) is preferable. When made of wood it consists of a square frame with projecting top and bottom pieces with boles through the centres to insert a stake. It is turned by one of the sides ez-

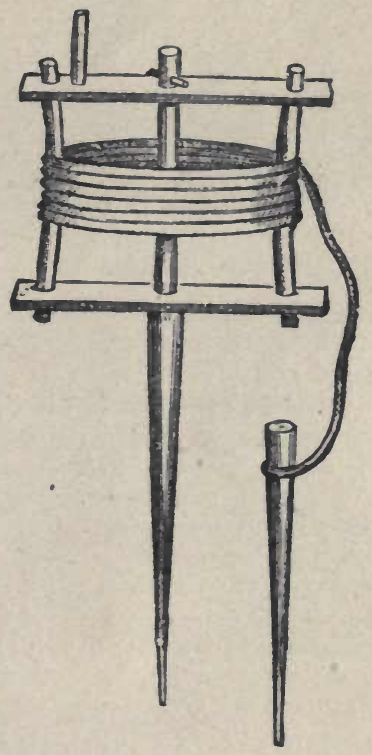

REEL AND LINE.

tending through the top piece for , andle. The other side should extend a couple of Inches through the bottom piece to hold the line when run off. In the flgure the handle is shown as inserted separately, which is not necessary ; the projection above referred to is not shown. A shorter stake will do for the other end of the line. Common three-stranded cord, about a quarter of an inch thick, is the most suitable for the line. To construct a Marking Rake, make the head three feet ten inches long by two lnches square. 
Bore four three-fourth-inch holes fourteen inches apart, commencing two inches from the ends; one hole in the centre; and holes at twelve, fifteen, sixteen and a half and eighteen inches each side of it. Make four teeth six inches long, an inch thick, and round them at the points. Secure them with a pin or key by the tops so they can be easily changed and adjusted to the different widths. The handle of the marker should be six feet long, split, and spread so as to form braces where it is fastened to the head.

Another form of marker is shown below, in which the teeth are not movable; they are fixed at the desired distances, on both sides of the head. The land being prepared for sowing, stick down the stake, run off the line, and lay it where it is desired to commence. Adjust the marking rake to fourteen inches, draw the outside tooth carefully by the line, and follow back and forth in the last mark until completed. After the ground is marked off, it should lie a little while for the surface to dry before commencing to sow the seed. It covers much better, and the soil will not stick to the wheel of the seed-sower. The best onion-growers now do not use seed-sowers with

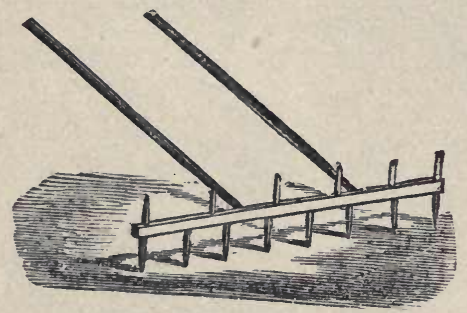

DRILL MARKER.

a roller attached. It packs the earth so hard that it bakes after a heavy rain and very much impedes the growth of the young plant, and it is not so easy in weeding to break the crust formed when rolled down flat as when the seed is covered by rakes or a light drag. It is of the utmost importance to get good seed-not only good, strong-growing seed, but seed that has been raised from good-sized, well-ripened onions. Imported seed cannot be trusted. The Second Early Red Onion is the best for a general crop. Sow four to six pounds to the acre-say about three seeds to an inch or five seeds to two inches ; cover half an inch.

As snon as the onions are up so they can be seen the length of the rows, run an onion-weeder or handcultivator through them, with the rakes adjusted so as not to throw the earth upon the young plants, and repeat often enough to prevent the growth of weeds. This will keep the ground perfectly clean between the rows. When they are just out of "the double," or when the flrst weeds begin to show, after cultivating, the ground should be raked lightly, diagonally across the rows wiih a common wooden hay rake. This will break the crust, destroy the weeds in the rows, and give the young plants a good start.

Early in June, when the onions are four or five inches high, sow about three bushels to the acre of not very coarse salt broadcast over them. After the second weeding, spread on a good dressing of wood ashes. They require three or four weedings in the rows; but if pains were taken in marking to keep the rows straight and uniform, the onion-weeder will run so close to them that there will be but few weeds to remove by hand.

When the tops have fallen and nearly died down, draw four rows together with a wooden rake, raking two rows at a time toward the other two rows. Pullforks are sometimes used, but in careless hands they pierce a good many onions. They may remain as raked together several days, or until sufficiently cured to strip; cut the tops about an inch from the onions. If they are stripped while the tops are partly green, they do not keep so well. After stripping, remove them to an outbuilding on a dry day, with a northwest wind, and spread over the floor, not more than a foot thick; turn them occasionally.

To keep onions in quantity through the winter; just before they are likely to freeze, and when perfectly dry, spread them eighteen inches thick on a tight floor in a barn or outbuilding which is underpinned so as to keep the cold air from freezing them too severely next the floor. Leave a space of two feet next the walls of the building on all sides; spread a sheet entirely over them, fill the space with fine hay, (rowen is the best) and tread it firmly; then cover the whole about two feet thick with the same, and the onions will ordinarily keep well. They should never be disturbed while frozen, but as soon as the frost is completely out in the spring, take off the covering and spread them all over the room, opening the doors and windows to give air in pleasant weather. If they are not well covered and the thermometer should fall to fifteen degrees below zero, some of them may freeze to death, and be soft when thawed.

White onions are the worst to keep, on account of their gathering moisture so readily. They should be kept spread quite thinly on the floor in the light and where the air can circulate freely. Just before winter sets in, spread a few inches of straw on a floor, and place the onions on it four or five inches thick; let them freeze a little, then cover them with straw and let them remain undisturbed until spring; or put them into peach crates and cover with hay in the barn, or pile the crutes next the walls of a cool cellar. Onions are generally one of the most profitable crops, often yielding four hundred to six bundred, sometimes eight hundred, bushels to the acre. 


\section{THE ONION FLY.-Anthomyia Ceparam.}

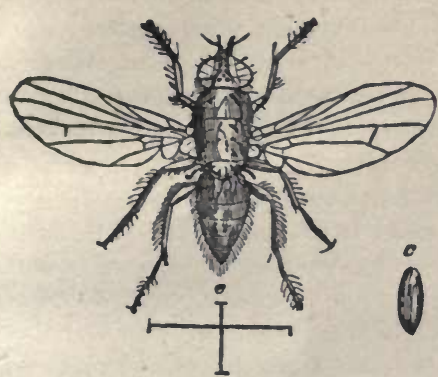

IIg. 1.

If travelling through the county of Essex, N. Y., a short time since, particularly along the beautiful plains in the vicinity of the Au-Sable River, I had my atten. tion repeatedly attracted to the witbered and sickly appest ance of nearly all the felds of onions, through which I passed. Upon inquiring the canse, I was in. variably told toat it was the effects of a worm, and that it was extremely doubtful if a single tuber in a bealthful condition would be obtained in a hundred p'ants. This excited my curiosity, and on raising the balbs from the earth, I bad little difflculty in recogniz$n g$ the larra of a Dipterous (two-winged) insect, belonging to a species which in England, as well as in nany cther parts of Europe, for the last twenty years, bave almost entirely destroyed the onion crops, upon tho cultivation of which 80 considorable an amount of labor and experience have been expended. To such a degree bave their ravages extended in those countries,

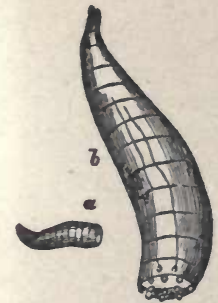

II. 8.

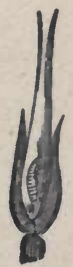

Ig. \&. that the husbandmen have been driven to the necessity of abandoning the culture of this important vegeta ble, not having yet met with any effcio: $t$ remedy for the destruction of their enemy.

Much uncertainty still seems to prevail among entomologists respecting the peculiar babits and instincts of this little depredator, and we greatly fear that they will long remain in ignorance, unless some interested and intelligent individual, residing on the spot, and having daily access to the plants, shall establish a veres of practical observations on their habits and in this manner trace them thruugh their various otage of existence, op to the perfoct fly. Until this is ac complished, and not till then, will we with any degree of cortainty be able to suggest any reasonable method for effeotually removing them. If it be not doro speedily, a knowledge of the prolific manner of their increase, makes it probable that they will, in the course of but a fow years, epread over the whole country, and almost, if not ontirely, obliterste this highly useful vegetable from our gardens.

This insect depredator is, I think, undoubtedly the Anthmyia ceparum, of Meigen, or a species so ilosely allied, as to differ but little from it in any of ito babits.

It is shown at e, fig. 1, somewhat magnified, tho sotual length being indicated by the perpendicular, and the spread of the wings by the horizontal line, below the cut of the fly; $c$ and $d$, same fign show the pupa, from which the insect emerges, $c$ being the natural size, and $d$ magnified. It belongs to the second gen. eral division of the Muscides, that of the Anthomyzides, which is composed of species, all of whom have greatly the appearance of common flies.

The larva of this insect, $a$ in Alg. 2, is about $t$ of an inch in length, fleshy, and of a white color. It is of a conical form, with a smooth and shining surface, and entirely free from any external superficial appendages. The incisions are finely granulate, and the last and largest segment is obliquely truncated at its base, upon which is placed a surrounding border of eight small knots, or projecting points, as seen at $b$, fig. 2 , repregenting the larva magnifled.

The female fiy deposits its eggs on the base of the stem near the surface of the ground, which in a fow days become hatched, the larvæ immediately penetrat ing between the leaves to the bulb, upor which it preys unseen; but the effects soon become visible, for

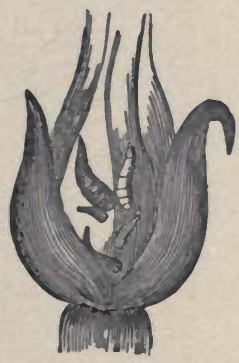

Mes.

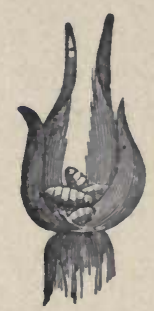

Fis. 6. the leaves turn yellow, fall prostrate on the ground, and quickly wither away. These are shown in fige 3 and 4. In the course of about two weeks they arrive 
at maturity, aad change to the pupa state, fig 6, and in from fifteen or twenty days more emerge the perfect Ay, fully prepared to accomplish their depredations by depositing their eggs upon the more healthy plants. As many as from one to five of the larræo were frequeatly to be met with on a single plant.

The perfect insect is abont half the size of the common bouse-fly, with a few thinly scattered hairs covermg the surface of the body. It is of an ash-gray color, the males being distinguished by a series of dark stripes upon the back. The head is marked with a brownish epot upon its aper. The wings are exceedingly transparent, exhibiting beautiful iridescent reflections from their surfaces, the shoulders of which are of an ocherybrown colcr, and the veins of brownish yellow.

This fly may not unfre ntly be met with in tho spring of the year, basking i the sunshine about the prindows of the neighboring dwellings. And from the circumstance of finding their larvw in the greatest profusion, committing their depredations in the middle and Latter parts of Angust, we are inclined to believe that they pass through several generations in a season, and that they probably make use of the seed of the plant, on which to deposit the egg for the larvæ of the ensuing spring. If this be so, steeping the seeds in brine, before sowing, we should suppose would be the proper remedy; if otherwise, the process will not materially affect their germination. They appear to show a dietinct predilection for the white onion, in preference - thes of any other color.
This insect it is exceedingly diffcult to destroy Strewing the earth with ashes has proved of little avail; powdered charcoal answers a much better purpose, and is generally in use in this section of country, but it should ouly be thrown over about two thirds of the bed, so as to leave a portion of the plants for them to resort to on being brought to the perfect state, and driven from their original resting-place. When they have been converted to the larva state and commenced their depredations, these plants should be pulled up and consumed by fire.

It has been recommended to prepare the beds as early in the sprnng as convenient, and suffer them to remain eight or ten days for the noxious plants to vegetate, then to cover them with straw to the depth of ten inches, and burn them over; after which, plant the seeds for the ensuing crop immediately. This pro. cess, it is stated, has proved perfectly succes=sul in driving away the insects and insuring good crops, and in addition to this, has furnished a capital top-dressing to the soil. Oninn-beds prepared from the hearthe upon which charcoal has been burned, have likewise been mentioned as producing the perfect vegetable, entirely free from the attacks of the thy.

Should the charcoal method here mentioned, be universally adopted, we have little doubt bnt that this insect depredator will in a short time become greatly reduced in number if not entirely destroyed, and afford a much better chance for a more healthfal crop of the onion plants bereantor. 




\section{RETURN TO: CIRCULATION DEPARTMENT 198 Main Stacks}

\begin{tabular}{cc|l|l}
\hline $\begin{array}{c}\text { LOAN PERIOD } \\
\text { Home Use }\end{array}$ & 1 & 2 & 3 \\
\hline & 4 & 5 & 6 \\
\hline
\end{tabular}

\section{ALL BOOKS MAY BE RECALLED AFTER 7 DAYS.}

Renewals and Recharges may be made 4 days prior to the due date. Books may be renewed by calling 642-3405.

\section{DUE AS STAMPED BELOW.}

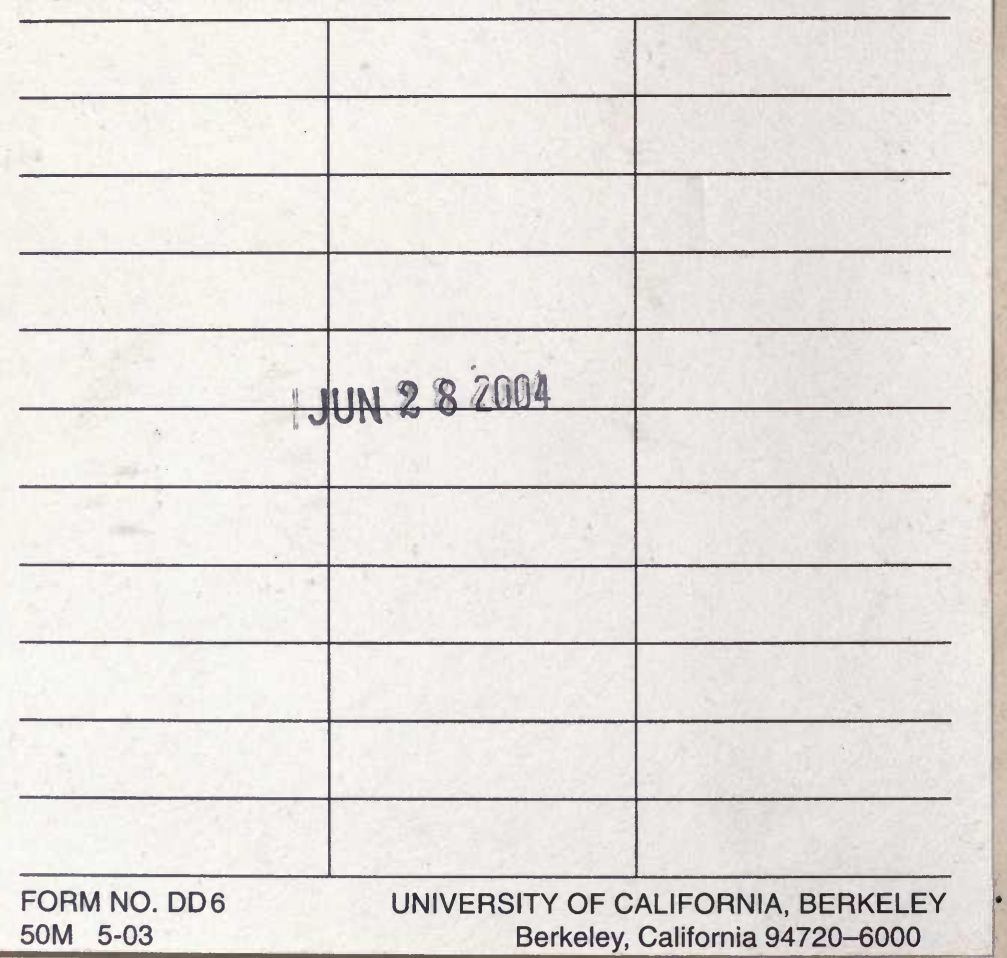


6hlos

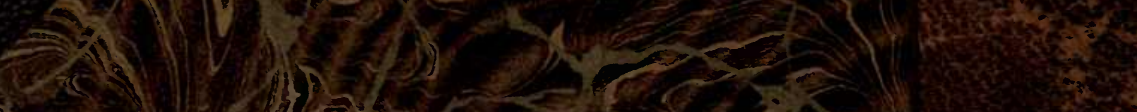

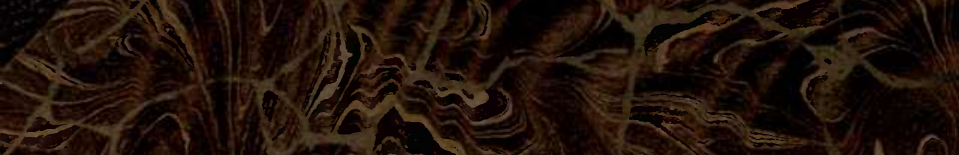

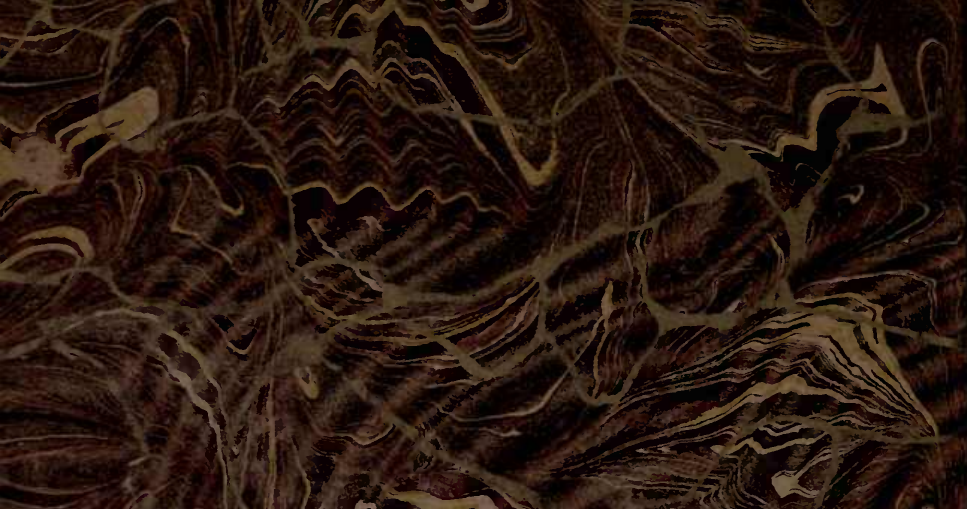

(1) 2)

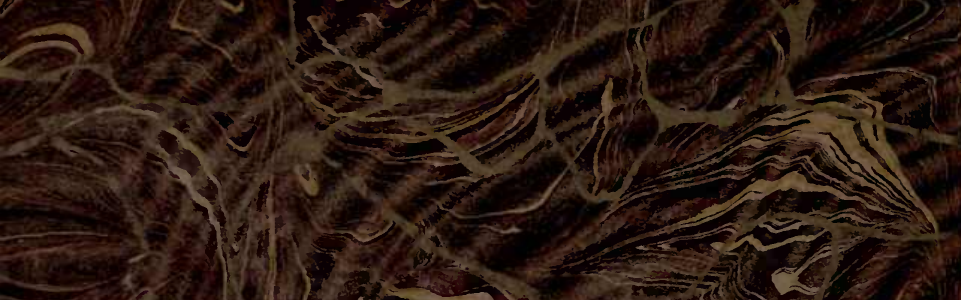

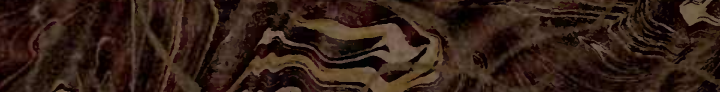

(1) 25

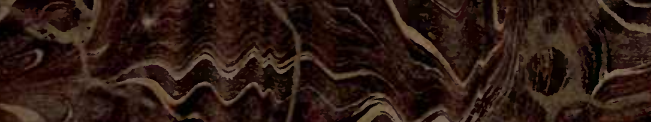

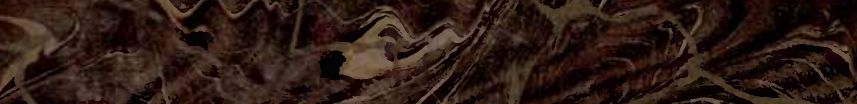

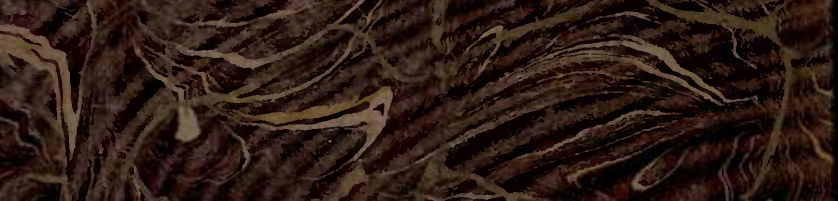

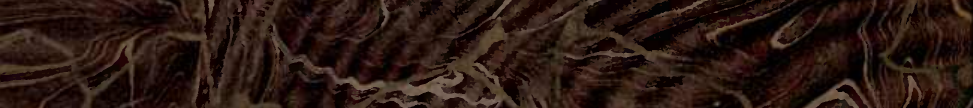

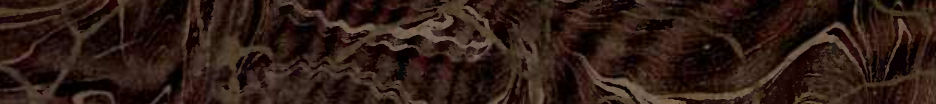

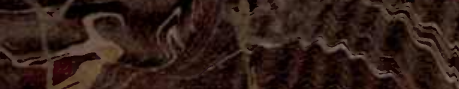
(2)

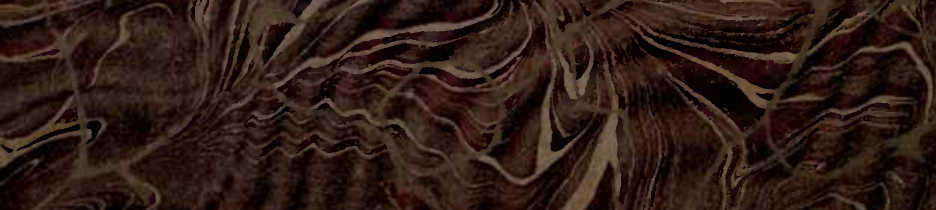
V) 130 